This item was submitted to Loughborough's Research Repository by the author.

Items in Figshare are protected by copyright, with all rights reserved, unless otherwise indicated.

\title{
Urban social sustainability at the neighbourhood scale: Measurement and the impact of physical and personal factors
}

PLEASE CITE THE PUBLISHED VERSION

https://doi.org/10.1080/13549839.2020.1829575

\section{PUBLISHER}

Taylor \& Francis (Routledge)

\section{VERSION}

AM (Accepted Manuscript)

\section{PUBLISHER STATEMENT}

This is an Accepted Manuscript of an article published by Taylor \& Francis in Local Environment: the international journal of justice and sustainability on 13 Oct 2020 , available online:

https://doi.org/10.1080/13549839.2020.1829575

\section{LICENCE}

CC BY-NC-ND 4.0

\section{REPOSITORY RECORD}

Larimian, Taimaz, Claire Freeman, Falli Palaiologou, and Negin Sadeghi. 2020. "Urban Social Sustainability at the Neighbourhood Scale: Measurement and the Impact of Physical and Personal Factors". Loughborough University. https://hdl.handle.net/2134/13012454.v1. 


\title{
Urban Social Sustainability at the Neighbourhood Scale: Measurement and the Impact of Physical and Personal Factors
}

\author{
Taimaz Larimian $^{\mathrm{a} *}$, Claire Freeman ${ }^{\mathrm{b}}$, Garyfalia Palaiologou $^{\mathrm{c}}$, Negin Sadeghi $^{\mathrm{d}}$
}

\begin{abstract}
:
Despite its theoretical and practical significance, urban social sustainability research lacks robust definition, conceptualisation and measurement. In addition, the factors influencing people's perceived feelings about their neighbourhood are underexplored. The aim of this study is two-fold: First, to develop and empirically test the urban social sustainability (USS) measurement model at the neighbourhood scale that captures the multifaceted nature of this complex phenomenon. Second, to use the proposed USS model to examine the role of different physical (urban form) and personal (socioeconomic) factors in promoting or weakening various aspects of neighbourhood social sustainability. We conducted factor analysis for testing the dimensionality, validity, and reliability of the USS model. Multiple regression analysis was also used to test the practical implications of the model. Our findings from 251 respondents in five case study neighbourhoods of Dunedin city, New Zealand, provide evidence that the effects of physical and personal factors can differ according to distinct USS dimensions. We found that out of the four physical factors, quality of urban design is the most influential factor, having a significant positive influence on three USS dimensions and the overall urban social sustainability. Among the personal factors, length of residence in a neighbourhood has the most influence on different USS dimensions.
\end{abstract}

Keywords: urban social sustainability, urban form (physical) factors, socio-economic (personal) factors, sustainable development, New Zealand

${ }^{a} \&{ }^{c}$ School of Architecture, Building and Civil Engineering, Loughborough University, United Kingdom

${ }^{b}$ School of Geography, University of Otago, Dunedin, New Zealand

${ }^{d}$ School of Architecture and Urban Planning, Islamic Azad University of Isfahan, Iran

Email: T.larimian@lboro.ac.uk 


\section{Introduction}

In recent years, sustainable urban development has attracted increasing attention from academics, urban planners, and policymakers alike. However, compared to the other pillars of sustainable development (i.e., economic and environmental), prior studies have paid less attention to social sustainability (Opp 2017). Review of the literature on urban social sustainability highlights four shortcomings that limit existing research.

First, despite overall consensus about the significance of social sustainability in the sustainable development agenda, extant literature displays wide heterogeneity in terms of the definition and measurement of urban social sustainability (Colantonio 2016; Shirazi and Keivani 2019). Different definitions, conceptualisations, and measurement schemes of urban social sustainability make it difficult to compare the findings of different studies and integrate previous findings into a coherent body of knowledge. Therefore, developing a theoretical conceptualisation and a reliable and valid measurement scale is a vital prerequisite to make progress in this area.

Second, the issue of urban social sustainability at the neighbourhood scale has received scant treatment in the literature (Shirazi and Keivani 2018; Hemani, Das, and Chowdhury 2017) hence, revealing a pressing need for more empirical investigations on this topic.

Third, despite the emphasis in the literature on the significant role of urban form in achieving urban social sustainability, it is still not clear how an urban area can be designed to meet the social needs of its residents (Bramley et al. 2009; Dempsey, Brown, and Bramley 2012). Discovering the urban form factors that facilitate or hinder the achievement of social sustainability in urban neighbourhoods is one of the primary, and yet unanswered, questions for urban social sustainability research (Hemani, Das, and Chowdhury 2017).

Fourth, the impact of personal (socio-economic) factors, such as income level, homeownership, and length of residence, on urban social sustainability is yet to receive rigorous empirical attention (Smith 2011). This is a particularly important issue for policymakers, as such differences may speak to the need for different policies and priorities designed to meet people's unique needs and expectations.

The aim of this study is two-fold. First, to address the lack of a reliable and valid measure of urban social sustainability at the neighbourhood scale. Building on the extant literature, we propose a more comprehensive and fine-grained measure for urban social sustainability (USS model) and empirically test its validity and reliability. Second, to investigate the application of the USS model in an urban setting by assessing the possible influences of four selected physical 
(urban form) factors and three personal (socio-economic) factors on people's perceived levels of urban social sustainability. The data used in the empirical tests are based on household questionnaire surveys collected from 251 respondents in five neighbourhoods of Dunedin city, New Zealand. The results of this study will provide researchers and policymakers with a better understanding of people's perceptions and expectations of their neighbourhood and, thereby, assist them in creating socially sustainable urban neighbourhoods that people would want to live in now and in the future.

\section{Urban Social Sustainability: Definition and Conceptualisation}

While having been acknowledged as the third dimension of sustainable development since the European Council (EC) meeting in 2000, social sustainability remains an evolving and under-represented concept in the sustainable development agenda (Larimian 2015). Table A1 in the Appendix provides a chronological review of measures of urban social sustainability used in previous studies and categorises them based on three criteria: i) dimensions, ii) indicators, and iii) scale of the study. The chronological review enables us to understand the evolution of conceptualisation and operationalisation of urban social sustainability over time. This provides the background knowledge to identify the dimensions related to neighbourhood scale and to shape the initial factorial structure of the USS model. As can be seen in Table A1, while traditionally the focus of social sustainability studies has been more on the macro scales (city and region), more recently the focus has been shifted towards micro scales (neighbourhood and community) (e.g., Shirazi and Keivani 2018; Hemani, Das, and Chowdhury 2017). Furthermore, there has been a transition from traditional "hard" measures of social sustainability (such as employment and poverty reduction) to more intangible and "soft" measures (such as social participation, and sense of place) (Colantonio 2016). The observed divergence in definitions, scales, and conceptualisations, at the first glance, may suggest social sustainability as being a "concept in chaos" (Vallance, Perkins, and Dixon 2011, 342). However, a deeper examination of the literature reveals some common dimensions comprising urban social sustainability, such as social participation (e.g. Bramley et al. 2009; Opp 2017).

In this paper, we extend former studies by proposing a new conceptualisation of urban social sustainability that reflects the nuances of this phenomenon and addresses its multidimensional and complex nature. For the purpose of this study, we only focus on the dimensions of social sustainability related to the built environment, using the neighbourhood 
as our scale of analysis. Following Larimian and Sadeghi $(2019,4)$, we define a socially sustainable neighbourhood as "one that provides residents with equitable access to facilities, services, and affordable housing; creates a viable and safe environment for interaction and participation in community activities; and promotes sense of satisfaction and pride in the neighbourhood in a way that people would like to live there now and in the future."

Accordingly, we conceptualise urban social sustainability in neighbourhoods based on six main dimensions identified in the literature, namely social participation, safety and security, social equity, neighbourhood satisfaction, social interaction, and sense of place. Table A2 in the Appendix shows the support that each USS dimension receives from researchers in the area of urban social sustainability at the neighbourhood scale. Each of the six dimensions of urban social sustainability is briefly explained below:

Social participation in a community is considered as a principal element of urban social sustainability. At the neighbourhood scale, social participation is associated with indicators such as participation in community activities and involvement in volunteer activities to improve the neighbourhood (Lewicka 2010). It has been proven that participation and interaction in community activities promote a sense of belonging to the neighbourhood and strengthen social cohesion and social networks within the community (Bramley et al. 2009).

Safety and security relate to the extent to which people feel safe to enjoy moving around their environment, to interact with other residents, and participate in community activities while feeling secure in their participation (Larimian, Zarabadi, and Sadeghi 2013). Both actual crime rate and perceived feeling of crime may hamper the achievement of social sustainability in neighbourhoods (Eizenberg and Jabareen 2017), being "two of the top deleterious ingredients of urban living" (Shaftoe 2000, 230).

Social equity, in the context of urban neighbourhoods, is defined as the extent to which people from different ages and socio-economic backgrounds have equitable access to a variety of public facilities and services and affordable housing (Dempsey et al. 2011). Social equity is an important ingredient of urban social sustainability as residents who use local facilities and services have higher chances to meet and interact with others and therefore develop social ties and community connectedness (Bramley et al. 2009).

Neighbourhood satisfaction is defined as "the degree to which the environment satisfies a person's need" (Smith 2011, 17) and refers to the difference between an individual's desired and actual quality of their neighbourhood (Wood, Frank, and Giles-Corti 2010). Determinants of neighbourhood satisfaction include housing satisfaction (Grillo, Teixeira, and Wilson 2010), 
residential stability (James, Carswell, and Sweaney 2009), and aesthetic appeal and quality of design of the neighbourhood (Fernández-Carro, Módenes, and Spijker 2015).

Social interaction is said to be the social glue that holds society together (Shirazi and Keivani 2017). People's social interactions within their local community "increase the perception of neighbourhood quality, which in turn creates residential satisfaction" (Smith 2011, 28). At the neighbourhood scale, social interaction can be measured by indicators such as knowing neighbours and frequency of meeting neighbours for different purposes (Dave 2011; Karuppannan and Sivam 2011; Lotfata and Ataöv 2019).

Sense of place is defined as an amalgam of shared emotional contact through a sense of membership and place attachment, and the feeling of having a "right to belong" (Talen 1999, 1370). Hemani, Das, and Chowdhury (2017) argue that sense of place is "an integral component of people's enjoyment of their built environment" (p. 173). The central tenet is that people who are proud of their neighbourhood, may feel stronger social connectedness to their community, and in turn, they may have a stronger desire to continue living in the neighbourhood and contribute to its development (Bramley et al. 2009).

\section{The Impact of Physical and Personal Factors on Urban Social Sustainability}

Urban form is a broad term and has been studied from different perspectives. Table A3 in the Appendix presents some of the commonly used definitions of urban form. The main goal of sustainable urban form is "to build urban environments without compromising the possibilities of future generations" (Kärrholm 2011, 107). The relationship between physical (urban form) factors and social sustainability has remained under-explored and not well understood. While there is no consensus on the most desirable urban forms for residential neighbourhoods, it has been widely acknowledged that urban form factors can have an important impact on achieving urban social sustainability (e.g., Burton and Mitchell 2006; Jenks, Kozak, and Takkanon 2013).

The factors comprising urban form may vary at different urban scales. Factors such as the structural form of a city within its region are present at the macro-scale (city-wide), while factors such as land-use mix and the layout of local street networks are used for measuring urban form at a more micro-scale (neighbourhood) (Bramley et al. 2006). Density is among the few urban form factors that can be measured at both micro and macro scales. A review of the literature reveals that previous studies have mainly focused on density, as the dominant measure of urban form (Dave 2011; Rani 2012), and therefore, tend to overlook the influence 
of other potentially important urban form factors on urban social sustainability. For instance, Smith (2011) maintains that the quality of urban design is a critical but overlooked factor of urban form. In this study, we concur with Arundel and Ronald $(2017,47)$ statement that "urban form beyond density does matter". Reflecting on this, in addition to density, we accounted for three important but neglected factors of urban form that can be measured at neighbourhood scale: land-use mix, quality of urban design, and sustainable transport. Below, we explain each of these factors briefly.

Density is arguably the most widely used urban form factor, and the one that has received the most scholarly attention with regard to its potential impact on urban social sustainability (Arundel and Ronald 2017). This is probably due to the fact that density is a key factor regarding the comparison between compact and low density (sprawl) developments (Dempsey, Brown, and Bramley 2012). Prior studies on the link between density and different aspects of urban social sustainability yielded mixed and inconclusive results. While some studies have found that high density has a diminishing impact on feelings of safety, residential satisfaction and sense of place (e.g., Larimian 2015; Dempsey et al. 2011), other findings emphasise the advantages of compactness such as providing accessible facilities, more affordable housing, efficient public transportation systems, and reduction of carbon emissions (e.g., Alexander and Tomalty 2002; Boyko and Cooper 2017).

Land-use mix refers to the diversity of functional land-uses such as industrial, residential, commercial, and institutional land-use (Jabareen 2006). The dominant land-use within the urban context is residential. However, in order for an urban area to function better, there needs to be a mixture of other land-uses (Dempsey et al. 2010). Land-use mix is believed to bring both positive and negative outcomes. On the plus side, there is evidence that mixed land-use may lead to lower levels of social segregation, economic viability, and higher social equity (Shirazi and Keivani 2019). A more mixed land-use is also associated with higher levels of community engagement and social participation, as it provides a greater variety, intensity, and number of participative activities for residents (Dempsey et al. 2010). On the flip side, more mixed land-use may have a negative impact on a sense of place and privacy in residential neighbourhoods, most notably in areas with high commercial land-use (Wood, Frank, and Giles-Corti 2010).

Transport infrastructure is arguably the most important factor of urban form in relation to environmental sustainability (Burton and Mitchell 2006; Jenks, Kozak, and Takkanon 2013). An extensive body of research indicates that urban areas that provide a safe and comfortable environment for cycling and walking movement while providing easy access to efficient public 
transport are linked to increasing liveability and sense of attachment among residents (Chan and Lee 2008; Lotfata and Ataöv 2019). Such neighbourhoods encourage walkability through design features such as improving street layout connectivity and calming the traffic (Kärrholm 2011). Findings also show that in neighbourhoods with a higher presence of car traffic and car parking, people's perceived feeling of safety and sense of place in the neighbourhood are lower (Hemani, Das, and Chowdhury 2017).

Quality of urban design is a predictor of sense of place and attachment, as well as neighbourhood satisfaction (Carmona 2019). A well-designed and maintained urban environment provides a friendly and healthy atmosphere in the neighbourhood that encourages physical activity and social interaction by the residents (Chan and Lee 2008). Urban design factors of a neighbourhood, such as the aesthetic appeal of the townscape, and design quality of buildings and public open spaces, contribute to residents' perceived levels of safety and security as well as the social and visual appeal of the neighbourhood (Armitage 2017; Lewicka 2010).

Another set of factors that are believed to influence people's perceptions of urban social sustainability are personal (socio-economic) factors such as people's income and homeownership. Separate studies by (Hemani, Das, and Chowdhury 2017) and (Dave 2011) indicate that people's length of residence in a neighbourhood has a positive association with their perceived feeling of safety, as it provides familiarity with the neighbourhood and therefore confidence in movement. A group of researchers found that people with higher incomes are less willing to interact with others and participate in community activities (e.g., Bramley et al. 2006; Rani 2012). However, Dave (2011) argues that households with lower incomes have fewer social contacts with their neighbours, as they are mostly unsatisfied with their situation, feel isolated, and have a lower sense of attachment to their environment. Homeownership has been linked to higher levels of neighbourhood satisfaction and sense of belonging as it allows people to settle and facilitates a sense of financial security (Evans 2009; Smith 2011). Similarly, length of residence is found to have a positive association with residents' perceived feeling of safety (Hemani, Das, and Chowdhury (2017); Dave (2011) and sense of place (Grillo, Teixeira, and Wilson 2010; Lewicka 2010; Smith 2011). 


\section{Materials and Methods}

\section{Study Design}

In this study, we designed a household questionnaire survey entitled "Your neighbourhood living experience" as the primary source of information. Ethical approval for the study was obtained from the University of Otago's Human Ethics Committee (HEC). Along with the questionnaire, we provided the respondents with an information letter explaining the research summary and aims. Prior to the data collection, the householders completed a consent form indicating their agreement to participate in the study in line with the standards of University of Otago's HEC. Five case study neighbourhoods from Dunedin, a medium-sized city for New Zealand, were investigated to develop and test the urban social sustainability (USS) model and to examine the potential effects of physical and personal factors on urban social sustainability. In the New Zealand context, a medium-sized city is a distinct entity that has a mostly urban character with a population of between 80,000 and 200,000 and acts as a major centre of activity within the region (Statistics New Zealand 2014). Five neighbourhoods were purposefully selected to reflect diverse urban neighbourhood forms in New Zealand's medium-sized cities and to represent a broad spectrum of various socio-economic status, different occupancy types, residential density, housing types, and land-use. In each neighbourhood, one main street and three residential streets were selected for data collection. The residential streets were selected in a way to be representative of the neighbourhood, located close to the main street and away from the neighbourhood boundaries. From the selected streets, every third house was chosen. In total, 864 anonymous questionnaires were mailed to resident's homes with a postage-paid reply envelope. Altogether, 251 usable questionnaires were returned, resulting in a response rate of $29.1 \%$. Detailed statistics about respondents and urban form charactristics and aerial maps and images of each neighbourhood are presented in Tables A4, A5, and A6 in the Appendix. Furthermore, Figure A1 shows the perceived significance of different problems in each neighbourhood.

\section{Measurements}

\section{Urban Social Sustainability (USS) Measurement Model}

Building on an extensive review of the literature, this study conceptualises urban social sustainability (USS) based on six dimensions, including social interaction, safety and security, social equity, social participation, neighbourhood satisfaction, and sense of place. 
Each of the USS dimensions is measured through selected indicators, and each indicator is associated with one question in the household questionnaire survey. We used seven-point Likert scales (ranging from $1=$ 'strongly disagree' to $7=$ 'strongly agree') to assess residents' perceptions regarding different aspects of living in their neighbourhood. Figure 1 shows a detailed overview of the indicators used for measuring USS dimensions.

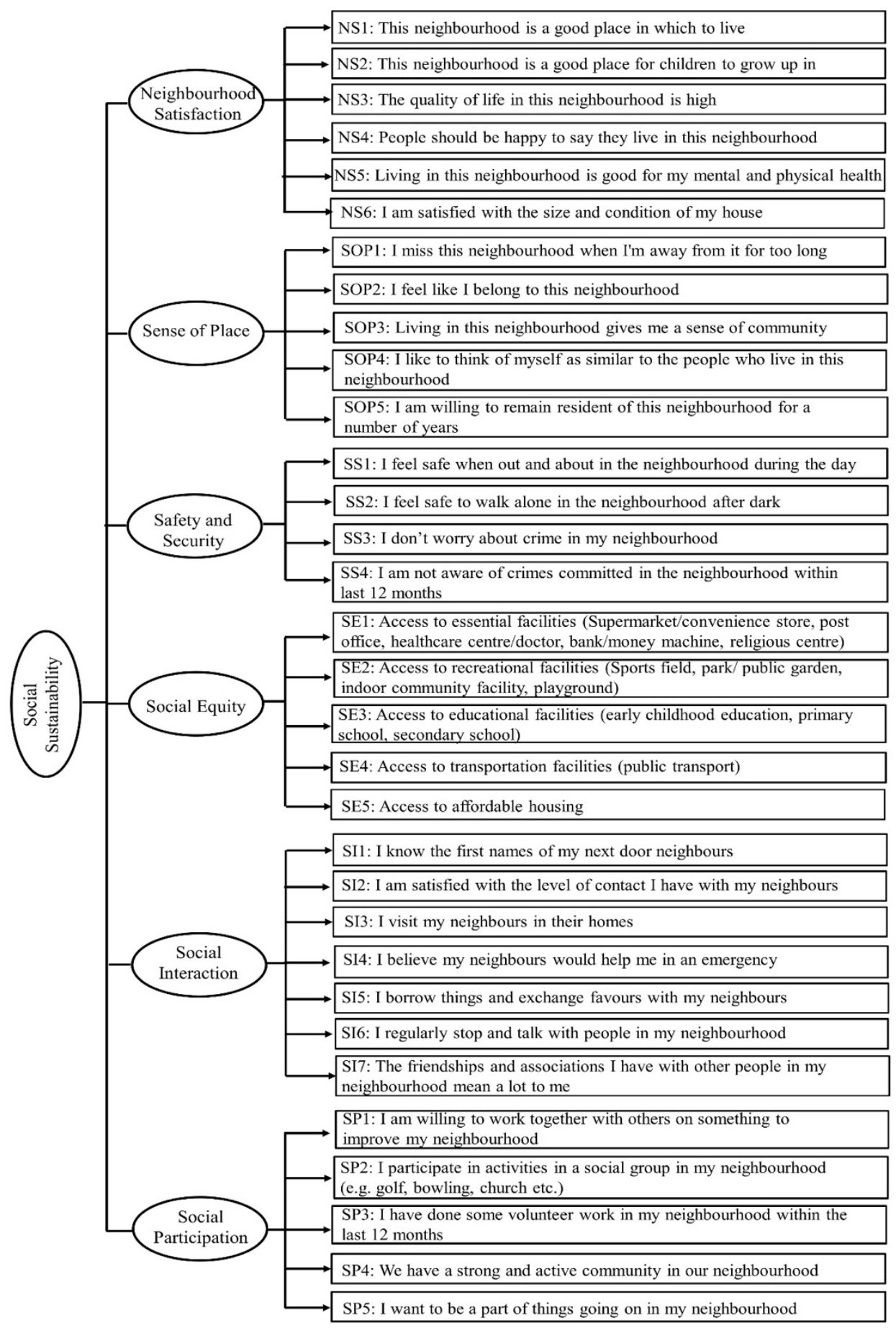

Figure 1. Urban social sustainability dimensions and measurement indicators. 


\section{Urban Form Measurement Model}

This study argues that the way individuals interpret the quality of their built environment including perceptions, feelings, and concerns about their neighbourhood, plays a critical role in their satisfaction with that environment. Factors such as satisfaction with the neighbourhood, appearance, and attractiveness of the neighbourhood, are "issues of subjective judgement made by the perceiver", and therefore, the value placed on these factors may vary from person to person (Dave 2011, 201). In addition, secondary data, such as census data or public reports, are often limited at the neighbourhood and street scale.

The focus of this study is on four selected physical (urban form) factors that could be measured at neighbourhood scale: density, quality of urban design, land-use mix, and transport infrastructure. Each urban form factor is measured through respondents' perceptions of selected indicators in their neighbourhood captured by seven-point Likert scales (ranging from $1=$ 'strongly disagree' to $7=$ 'strongly agree'). Each of the indicators for urban form factors is derived from the extant literature and previously validated surveys (e.g., Dave 2011; Dempsey et al. 2010; Rani 2012). Using already validated questions from previous studies allows us to take account of whether the questions have been proven to work and enables us to compare and contrast our results with existing studies. Figure 2 provides a detailed overview of the measurement indicators of each urban form factor. 


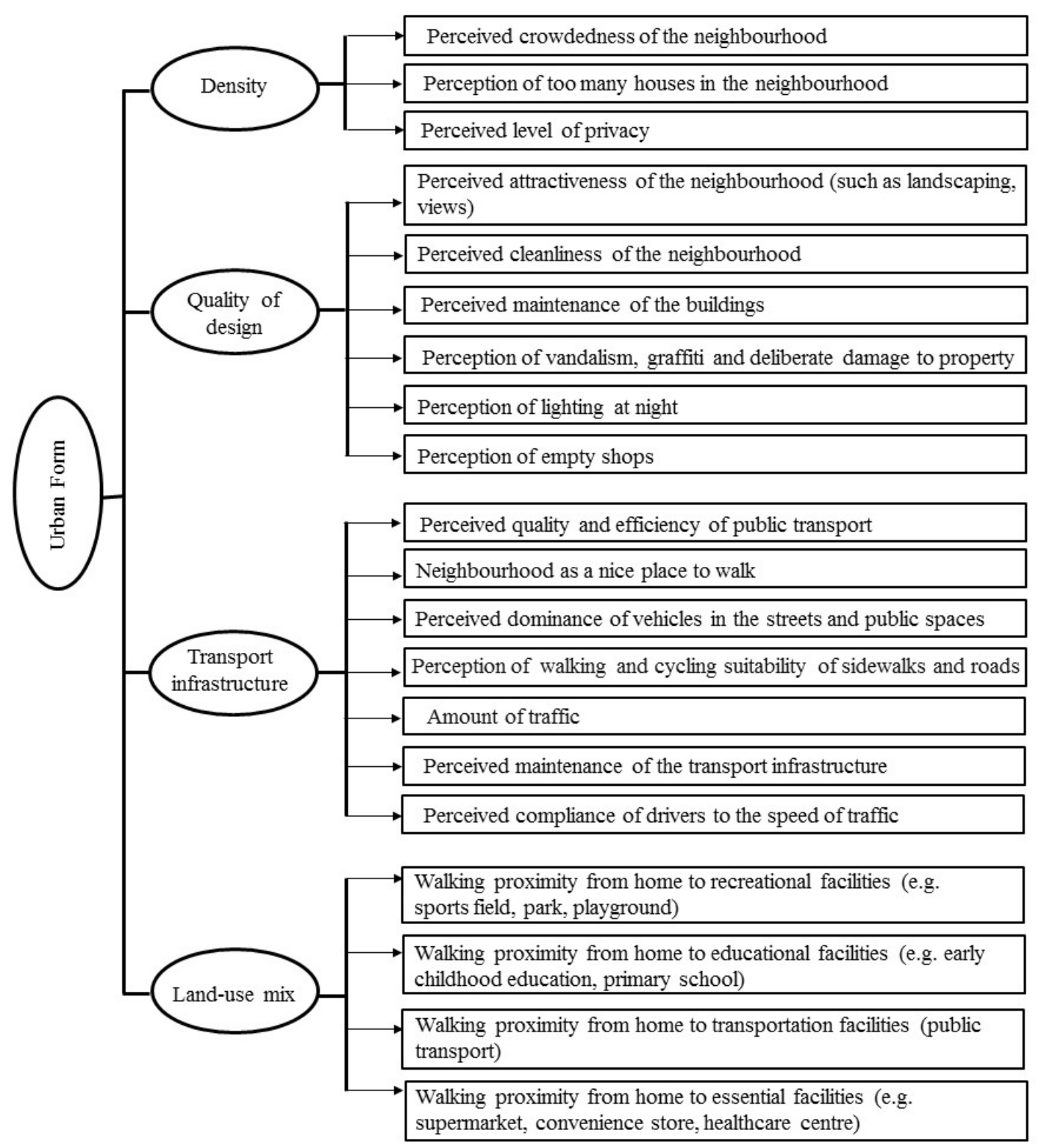

Figure 2. Urban form factors and measurement variables.

\section{Statistical Analysis}

In this study, we followed two separate and yet related steps of data analysis. The first step focuses on the development and validation of the USS model and urban form model. For this step, we applied the standard procedure for scale development including both exploratory factor analysis (EFA) and confirmatory factor analysis (CFA), for shaping both USS and urban form measurement models and testing the reliability and validity of these models. Figure A2 shows the process of development of these models and different stages of using factor analysis. Content, discriminant and convergent validity tests were performed to assess the validity of the models. Building the measurement model based on an extensive review of 
the relevant literature and carrying out pre-test can support content validity (Hair et al. 2010; Bagozzi and Yi 1988). Convergent validity is ensured when the standardised loading of indicators on their respective dimensions are above 0.50 , and the average of variance explained (AVE) score for all the dimensions exceeds the threshold value of 0.5 (Hair et al. 2010). Discriminant validity evaluates the extent to which a given dimension is distinct from other dimensions and is supported when the square root of AVE for each dimension is greater than the correlation coefficient between it and any other dimension in the USS model. Finally, we assessed the goodness of fit of the model with several indices. As a rule of thumb, we assume good model fit when Root Mean Square Error of Approximation (RMSEA) < 0.05, Standardized Root Mean Square Residual (SRMR) $<0.08$, and Chi-Square/df $<3$.

The second step of data analysis applied the proposed USS model to assess the influence of physical (urban form) and personal (socio-economic) factors on urban social sustainability using multiple regression analysis (Figure 3). In total, four physical factors of density, transport infrastructure, land-use mix, and quality of design were selected for the purpose of this study. Additionally, three selected personal factors of income, length of residence, and homeownership were investigated for their potential impact on each USS dimension and overall urban social sustainability. We also included in our analysis a number of demographic factors as control variables, as they have the potential to influence people's perception of urban social sustainability (Dave 2011; Lewicka 2010; Grillo, Teixeira, and Wilson 2010). These control variables include gender, age, education, and marital status. In this step, ordinary least squares (OLS) regression modelling was conducted using SPSS (version 18). Also, the associated P-value for each regression coefficient $(\beta)$ was used to evaluate the statistical significance of each set of multiple regression analysis. This study follows the recommendation by Hair et al. (2010) and considers the P-values below 0.05 to be statistically significant. 


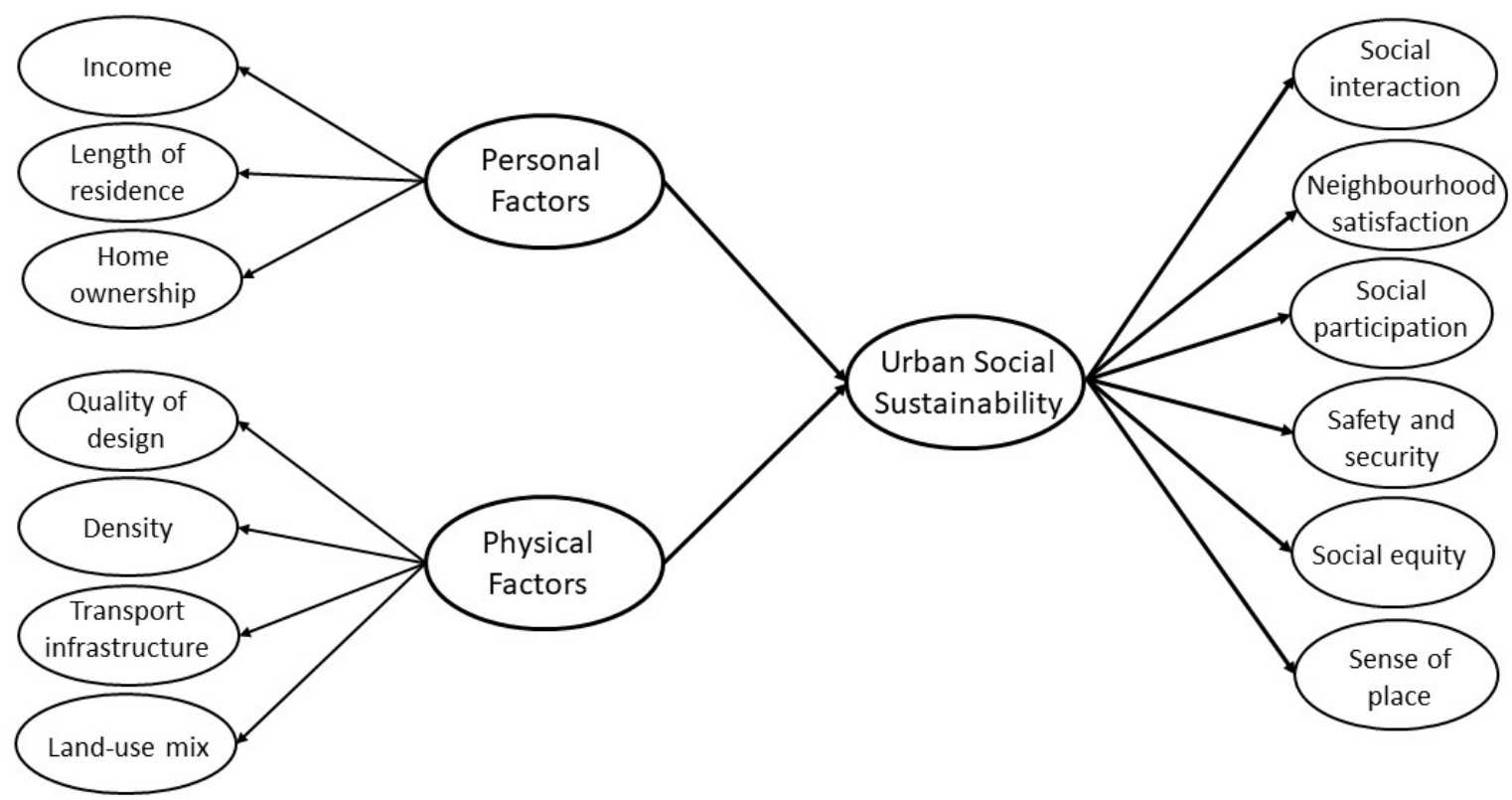

Figure 3. The relationship between physical and personal factors and dimensions of urban social sustainability.

\section{Results}

\section{Reliability and Validity of USS Model and Urban Form Model}

Following the procedure recommended by Hair et al. (2010), we conducted EFA analysis to assess the dimensionality of the USS and urban form models. EFA analysis approved the anticipated six-dimensional structure of urban social sustainability. As a part of the EFA analysis, the indicators that either had a low factor loading (below 0.5) or high cross-loading in more than one dimension were sequentially removed to ensure a stronger measurement model (for a detailed explanation of the EFA process see (Hair et al. 2010)).

Table 1 presents the final measurement indicators of the USS model, EFA factor loadings, percentage of variance explained, and internal reliabilities (i.e., Cronbach's alpha values). The Cronbach's alphas of all dimensions exceeded the commonly used threshold value of 0.6 (Bagozzi and Yi 1988), which indicates acceptable internal reliability in this exploratory study. 
Table 1. Results of exploratory factor analysis $(\mathrm{N}=251)$

\begin{tabular}{lcccc}
\hline Dimensions and indicators & $\begin{array}{c}\text { Factor } \\
\text { loading } \\
\text { range }\end{array}$ & $\begin{array}{c}\text { Eigenv } \\
\text { alues }\end{array}$ & $\begin{array}{c}\text { \% variance } \\
\text { explained }\end{array}$ & $\begin{array}{c}\text { Cronbach's } \\
\text { Alpha }\end{array}$ \\
\hline $\begin{array}{l}\text { 1. Social Interaction } \\
\text { (Indicators: SI1, SI2, SI3, SI5, SI6, SI7) }\end{array}$ & $0.65-0.81$ & 5.69 & 23.74 & 0.85 \\
$\begin{array}{l}\text { 2. Neighbourhood Satisfaction } \\
\text { (Indicators: NS1, NS2, NS3, NS5, NS6) }\end{array}$ & $0.64-0.82$ & 3.05 & 12.70 & 0.83 \\
$\begin{array}{l}\text { 3. Social Participation } \\
\text { (Indicators: SP1, SP2, SP3) }\end{array}$ & $0.70-0.92$ & 2.15 & 8.97 & 0.82 \\
$\begin{array}{l}\text { 4. Safety and Security } \\
\text { (Indicators: SS2, SS3, SS4) }\end{array}$ & $0.74-0.82$ & 1.64 & 6.84 & 0.76 \\
$\begin{array}{l}\text { 5. Social Equity } \\
\text { (Indicators: SE1, SE3, SE4, SE5) }\end{array}$ & $0.56-0.85$ & 1.50 & 6.25 & 0.71 \\
$\begin{array}{l}\text { 6. Sense of Place } \\
\text { (Indicators: SOP2, SOP3, SOP5) }\end{array}$ & $0.71-0.77$ & 1.28 & 5.36 & 0.69 \\
\hline
\end{tabular}

Note. Extraction method: principal component analysis; Rotation method: Promax with Kaiser Normalisation $\mathrm{KMO}=0.801$; Bartlett spherical test $=2508.615$; significance $=0.000$

In addition, CFA analysis was applied to evaluate the validity of the USS and urban form models and to estimate the composite reliability (CR) of each dimension in the models. Here, for the sake of brevity, we only reported the estimates related to the USS model. The CR of all six USS dimensions range from 0.62 to 0.87 , which exceed the 0.60 threshold and verify high internal consistency and reliability of these dimensions in the USS model (Bagozzi and Yi 1988). We also found support for the content, discriminant, and convergent validity of the USS model. The AVE scores for all the dimensions exceeded the threshold of 0.5 , and all the indicators loaded significantly on their intended dimension providing evidence of convergent validity (Bagozzi and Yi 1988). Discriminant validity was supported because the square root of AVE for each dimension was greater than the correlation coefficient between it and any other dimensions.

Finally, we assessed the overall model adequacy (goodness-of-fit) with several indices exhibiting a good fit of the USS model to the data: RMSEA $=0.04$, SRMR $=0.07$, ChiSquare/df $=1.47$. The goodness of fit results demonstrate that six dimensions accurately represent the urban social sustainability concept. Overall, factor analysis results indicate that the loadings of indicators in the USS model are strong, and the six dimensions explain over $63.86 \%$ of the total variance, indicating a strong model fit.

\section{Regression Analysis Results}

In the second step of data analysis, multiple regression analyses were conducted to investigate the influence of physical and personal factors on USS dimensions using the 
developed USS model from the previous step. The results of regression analysis in relation to the regression coefficients between physical factors and urban social sustainability appear in Table 2. As an example, in the first column of Table 2, the positive and significant estimated coefficient associated with transport infrastructure $(\beta=0.187, \mathrm{P}<0.001)$ and quality of urban design $(\beta=0.090, p<0.001)$, suggest that there are positive relationships between each of these two urban form factors and neighbourhood satisfaction.

Table 2. Multiple regression analyses between physical (urban form) factors and USS dimensions

\begin{tabular}{|c|c|c|c|c|c|c|c|}
\hline & $\begin{array}{c}\text { Social } \\
\text { interaction }\end{array}$ & $\begin{array}{l}\text { Neighbourhood } \\
\text { satisfaction }\end{array}$ & $\begin{array}{c}\text { Social } \\
\text { participation }\end{array}$ & $\begin{array}{c}\text { Safety } \\
\text { and } \\
\text { security }\end{array}$ & $\begin{array}{l}\text { Social } \\
\text { equity }\end{array}$ & $\begin{array}{l}\text { Sense of } \\
\text { place }\end{array}$ & $\begin{array}{c}\text { Overall } \\
\text { social } \\
\text { sustainability }\end{array}$ \\
\hline \multirow{2}{*}{ Constant } & $3.411^{*}$ & $6.223^{* * *}$ & 1.769 & $6.414^{* * *}$ & $2.269^{\dagger}$ & 0.690 & $3.463^{* * *}$ \\
\hline & (1.435) & $(0.345)$ & (2.101) & (1.667) & (1.156) & (1.469) & $(0.712)$ \\
\hline \multirow{2}{*}{$\begin{array}{l}\text { Transport } \\
\text { infrastructure }\end{array}$} & 0.050 & $0.187^{* * *}$ & 0.144 & -0.080 & -0.018 & $0.371^{*}$ & 0.109 \\
\hline & $(0.168)$ & $(0.041)$ & $(0.246)$ & $(0.196)$ & $(0.136)$ & $(0.172)$ & $(0.084)$ \\
\hline \multirow{2}{*}{$\begin{array}{l}\text { Land-use } \\
\text { mix }\end{array}$} & $0.138^{\dagger}$ & $-0.099^{* * *}$ & 0.169 & -0.110 & $0.145^{*}$ & -0.11 & 0.022 \\
\hline & $(0.077)$ & $(0.019)$ & $(0.113)$ & $(0.090)$ & $(0.062)$ & $(0.079)$ & $(0.038)$ \\
\hline \multirow{2}{*}{$\begin{array}{l}\text { Quality of } \\
\text { design }\end{array}$} & 0.046 & $0.090^{* * *}$ & -0.084 & $0.078^{*}$ & -0.024 & $0.377^{* * *}$ & $0.080^{*}$ \\
\hline & $(0.065)$ & $(0.016)$ & $(0.094)$ & $(0.075)$ & $(0.052)$ & $(0.066)$ & $(0.032)$ \\
\hline \multirow{2}{*}{ Density } & -0.109 & $-0.705^{* * *}$ & 0.015 & $-0.477^{*}$ & $0.236^{\dagger}$ & -0.061 & $-0.189^{*}$ \\
\hline & $(0.172)$ & $(0.041)$ & $(0.252)$ & $(0.200)$ & $(0.138)$ & $(0.176)$ & $(0.085)$ \\
\hline \multirow{2}{*}{ Gender } & 0.002 & $0.060^{\dagger}$ & -0.025 & -0.081 & -0.124 & -0.147 & -0.052 \\
\hline & $(0.143)$ & $(0.035)$ & $(0.210)$ & $(0.167)$ & $(0.116)$ & $(0.147)$ & $(0.071)$ \\
\hline \multirow{2}{*}{ Age group } & $0.186^{* * *}$ & $0.016^{\dagger}$ & $0.232^{* * *}$ & 0.068 & -0.011 & $0.214^{* * *}$ & $0.118^{* * *}$ \\
\hline & $(0.040)$ & $(0.010)$ & $(0.059)$ & $(0.046)$ & $(0.032)$ & $(0.041)$ & $(0.020)$ \\
\hline \multirow{2}{*}{ Education } & -0.051 & -0.012 & -0.047 & -0.027 & 0.045 & -0.016 & -0.018 \\
\hline & $(0.061)$ & $(0.015)$ & $(0.089)$ & $(0.071)$ & $(0.049)$ & $(0.062)$ & $(0.030)$ \\
\hline \multirow{2}{*}{ Marital Status } & 0.101 & 0.045 & -0.034 & 0.159 & 0.052 & 0.124 & 0.075 \\
\hline & $(0.133)$ & $(0.032)$ & $(0.195)$ & $(0.155)$ & $(0.107)$ & $(0.136)$ & $(0.066)$ \\
\hline $\mathrm{R}^{2}$ & 0.170 & 0.900 & 0.104 & 0.089 & 0.046 & 0.316 & 0.374 \\
\hline $\mathrm{F}$ & $6.190^{* * *}$ & $272.627^{* * *}$ & $3.497^{* *}$ & $2.964^{* *}$ & 1.445 & $14.000^{* * *}$ & $18.036^{* * *}$ \\
\hline
\end{tabular}

Notes: Figures in the table are unstandardised beta coefficients $(\beta)$; Standard errors are in parentheses; $\uparrow \mathrm{p}<0.1$; $* \mathrm{p}<0.05 ; * * \mathrm{p}<0.01 ; * * * \mathrm{p}<0.001$ 
It is evident from the findings that some of the personal factors are significantly related to dimensions of urban social sustainability and could influence people's perceived levels of social sustainability of their neighbourhood (Table 3). For instance, Table 3 shows that length of residence $(\beta=0.380, \mathrm{P}<0.001)$ is positively associated with social participation, while income $(\beta=-0.086, \mathrm{P}<0.05)$ has a negative relationship with social participation. Based on our results, out of four demographic factors that have been used as control variables, only age was found to be positively associated with social interaction, in that older respondents had higher levels of social interaction.

Table 3. Multiple regression analyses between personal (socioeconomic) factors and USS dimensions

\begin{tabular}{|c|c|c|c|c|c|c|c|}
\hline & $\begin{array}{c}\text { Social } \\
\text { interaction }\end{array}$ & $\begin{array}{l}\text { Neighbourhood } \\
\text { satisfaction }\end{array}$ & $\begin{array}{c}\text { Social } \\
\text { participation }\end{array}$ & $\begin{array}{c}\text { Safety } \\
\text { and } \\
\text { security }\end{array}$ & $\begin{array}{l}\text { Social } \\
\text { equity }\end{array}$ & $\begin{array}{l}\text { Sense } \\
\text { of } \\
\text { place }\end{array}$ & $\begin{array}{c}\text { Overall } \\
\text { social } \\
\text { sustainability }\end{array}$ \\
\hline Constant & $\begin{array}{l}1.379^{*} \\
(0.556)\end{array}$ & $\begin{array}{l}1.737^{* * *} \\
(0.311)\end{array}$ & $\begin{array}{l}4.679^{* * *} \\
(0.818)\end{array}$ & $\begin{array}{l}3.122^{* * *} \\
(0.762)\end{array}$ & $\begin{array}{l}3.251^{* * *} \\
(0.546)\end{array}$ & $\begin{array}{c}1.156 \\
(0.725)\end{array}$ & $\begin{array}{l}2.554^{* * *} \\
(0.284)\end{array}$ \\
\hline Income & $\begin{array}{l}-0.014 \\
(0.025)\end{array}$ & $\begin{array}{l}0.046^{* *} \\
(0.014)\end{array}$ & $\begin{array}{l}-0.086^{* *} \\
(0.036)\end{array}$ & $\begin{array}{l}0.140^{* * *} \\
(0.034)\end{array}$ & $\begin{array}{l}-0.034 \\
(0.024)\end{array}$ & $\begin{array}{c}0.048 \\
(0.032)\end{array}$ & $\begin{array}{c}0.017 \\
(0.013)\end{array}$ \\
\hline $\begin{array}{l}\text { Length of } \\
\text { residence }\end{array}$ & $\begin{array}{l}0.716^{* * *} \\
(0.067)\end{array}$ & $\begin{array}{l}0.694^{* * *} \\
(0.038)\end{array}$ & $\begin{array}{l}0.380^{* * *} \\
(0.099)\end{array}$ & $\begin{array}{l}0.225^{*} \\
(0.092)\end{array}$ & $\begin{array}{c}0.034 \\
(0.066)\end{array}$ & $\begin{array}{l}0.461^{* * *} \\
(0.088)\end{array}$ & $\begin{array}{l}0.418^{* * *} \\
(0.034)\end{array}$ \\
\hline $\begin{array}{l}\text { Home } \\
\text { ownership }\end{array}$ & $\begin{array}{l}0.473^{* *} \\
(0.143)\end{array}$ & $\begin{array}{l}0.132^{\dagger} \\
(0.080)\end{array}$ & $\begin{array}{l}2.013^{* * *} \\
(0.211)\end{array}$ & $\begin{array}{c}0.163 \\
(0.196)\end{array}$ & $\begin{array}{c}0.019 \\
(0.141)\end{array}$ & $\begin{array}{l}-0.065 \\
(0.187)\end{array}$ & $\begin{array}{l}0.412^{* * *} \\
(0.073)\end{array}$ \\
\hline Gender & $\begin{array}{l}-0.087 \\
(0.119)\end{array}$ & $\begin{array}{l}-0.027 \\
(0.067)\end{array}$ & $\begin{array}{l}-0.053 \\
(0.176)\end{array}$ & $\begin{array}{l}-0.157 \\
(0.164)\end{array}$ & $\begin{array}{l}-0.106 \\
(0.117)\end{array}$ & $\begin{array}{l}-0.209 \\
(0.156)\end{array}$ & $\begin{array}{l}-0.106^{\dagger} \\
(0.061)\end{array}$ \\
\hline Age group & $\begin{array}{l}0.073^{*} \\
(0.036)\end{array}$ & $\begin{array}{l}-0.016 \\
(0.020)\end{array}$ & $\begin{array}{c}0.032 \\
(0.052)\end{array}$ & $\begin{array}{c}0.054 \\
(0.049)\end{array}$ & $\begin{array}{l}-0.020 \\
(0.035)\end{array}$ & $\begin{array}{l}0.203^{* * *} \\
(0.046)\end{array}$ & $\begin{array}{l}0.055^{* *} \\
(0.018)\end{array}$ \\
\hline Education & $\begin{array}{l}-0.020 \\
(0.051)\end{array}$ & $\begin{array}{l}-0.023 \\
(0.028)\end{array}$ & $\begin{array}{l}-0.065 \\
(0.075)\end{array}$ & $\begin{array}{l}-0.019 \\
(0.069)\end{array}$ & $\begin{array}{c}0.057 \\
(0.050)\end{array}$ & $\begin{array}{l}-0.001 \\
(0.066)\end{array}$ & $\begin{array}{l}-0.012 \\
(0.026)\end{array}$ \\
\hline Marital Status & $\begin{array}{c}0.054 \\
(0.111)\end{array}$ & $\begin{array}{c}0.044 \\
(0.062)\end{array}$ & $\begin{array}{c}0.053 \\
(0.164)\end{array}$ & $\begin{array}{c}0.207 \\
(0.153)\end{array}$ & $\begin{array}{c}0.031 \\
(0.109)\end{array}$ & $\begin{array}{c}0.114 \\
(0.145)\end{array}$ & $\begin{array}{c}0.084 \\
(0.057)\end{array}$ \\
\hline $\mathrm{R} 2$ & 0.426 & 0.627 & 0.374 & 0.124 & 0.020 & 0.233 & 0.542 \\
\hline $\mathrm{F}$ & $22.487^{* * *}$ & $50.868^{* * *}$ & $18.067^{* * *}$ & $4.274^{* * *}$ & 0.604 & $9.173^{* * *}$ & $35.776^{* * *}$ \\
\hline
\end{tabular}

Notes: Figures in the table are unstandardised beta coefficients $(\beta)$; Standard errors are in parentheses; $\uparrow \mathrm{p}<0.1$; $* \mathrm{p}<0.05 ; * * \mathrm{p}<0.01 ; * * * \mathrm{p}<0.001$ 


\section{Discussion of Findings}

In this study, we have developed and validated the USS model that measures the level of urban social sustainability at the neighbourhood scale. We emphasise the importance of people's satisfaction and perceptions in defining urban social sustainability. We argue that the level of urban social sustainability is subject to the interpretation of people and their judgment about their neighbourhood. Our findings confirm that urban social sustainability is a multidimensional second-order concept that comprises six dimensions of social participation, social equity, social interaction, sense of place, safety and security, and neighbourhood satisfaction. Failure to consider each of these dimensions may lead to an incomplete picture of this concept. In the following section, we discuss the impact of physical and personal factors on different USS dimensions.

\section{Physical Factors which are Associated with the Dimensions of Urban Social Sustainability}

Urban form can be measured by both objective and subjective factors (Dempsey et al. 2010; Williams, Dair, and Lindsay 2010). With only a few exceptions (e.g., Rani 2012; Smith 2011), prior studies have paid less attention to subjective measures of urban form, even though "perceptions of neighbourhood features play as much of a role in shaping behaviour as actual characteristics" (Wood, Frank, and Giles-Corti 2010, 1381). For instance, density has been mainly measured objectively by the ratio of dwelling units or people to land area, and transport infrastructure has been measured by indicators such as the number of buses per hour during weekday and number and spread of bus stops (e.g., Dempsey et al. 2010; Jabareen 2006). However, our focus was to develop subjective measures of density (e.g., perceived crowdedness of the neighbourhood) and transport infrastructure (e.g., perceived quality and efficiency of public transport, and perceived walkability of the neighbourhood). Quality of urban design has also been mainly measured objectively, by employing indicators such as the "proportion of 'active' building frontage per street", "assessment of pavement condition", and "amount of litter per street" (Dempsey 2009, 324). For the purpose of this study, our subjective measure of quality of design included indicators such as perceived cleanliness of the neighbourhood and maintenance of the buildings (Figure 2).

In this section, we discuss the influence of the four studied physical (urban form) factors on each dimension of urban social sustainability and overall urban social sustainability. 
Neighbourhood satisfaction. Our results indicated that physical factors have mixed effects on people's perceived levels of neighbourhood satisfaction. We found that better transport infrastructure is significantly related to having higher neighbourhood satisfaction. In addition, our results illustrate a positive relationship between quality of urban design and neighbourhood satisfaction, indicating that the aesthetic characteristics of urban environments, such as the attractiveness of the streetscape, can improve people's satisfaction with their environment. Both high perceived density and land-use mix had negative associations with neighbourhood satisfaction. These associations are in line with studies that found lower satisfaction in high-density areas with land-use intensity, due to more crowding, increased levels of noise, lower sense of privacy, and more strain on community facilities and services (Wood, Frank, and Giles-Corti 2010; Smith 2011).

Social interaction. Our results revealed that in areas with more mixed land-use, people are more encouraged to interact with each other and therefore have stronger social networks with other members of the community. In fact, land-use mix decreases car dependence and encourages more pedestrian activities for different purposes and at various times, and therefore increases people's opportunity to interact and develop social ties (Bramley et al. 2009; Wood, Frank, and Giles-Corti 2010; Lotfata and Ataöv 2019).

Safety and security. Our findings revealed that both density and quality of urban design had significant effects on safety and security but in opposite directions. Quality of urban design had a positive association with people's perceived feeling of safety and security. This is in line with the crime prevention through environmental design (CPTED) approach that indicates proper design and effective use of the built environment along with target hardening and maintenance strategies can reduce the incidence of crime, fear of crime and, to a greater extent, improve the level of urban social sustainability (Wood, Frank, and Giles-Corti 2010; Armitage 2017). Density was negatively associated with safety, meaning that in environments with higher perceived density, people had a lower sense of safety and security. This can be explained by the fact that high perceived crowding of people may decrease natural surveillance and territoriality, and therefore result in low feelings of security and safety in public spaces (Cozens, Love, and Nasar 2015).

Social participation. No significant relationships were observed between any of the four selected factors of urban form and people's levels of social participation. However, some scholars state that the urban form features of a neighbourhood should provide an enjoyable and comfortable atmosphere for people to increase their willingness to participate in community activities (Williams, Dair, and Lindsay 2010; Choguill 2008). These findings also differ from 
studies that indicate higher land-use mix is associated with more community engagement and social participation due to providing greater variety, intensity, and number of activities for residents to participate (Hemani et al. 2017; Bramley et al. 2010).

Social equity. Our results indicated that in higher density areas, people had better access to facilities, services, and affordable housing. The land-use mix was also positively related to social equity. This highlights the significant role of adding places to shop, work, and socially interact within the residential neighbourhoods to improve urban dynamism and therefore increase people's satisfaction with and attachment to their neighbourhood (Talen 1999; Karuppannan and Sivam 2011; Dempsey et al. 2010).

Sense of place. Transport infrastructure showed a positive association with sense of place. We assert that pedestrian-oriented environments with accessible and safe cycling and walking routes and efficient public transport enhance people's sense of pride and belonging to their environment. In addition, quality of urban design was shown to have a positive influence on people's sense of place. This finding concurs with previous literature, indicating that people feel more attached to their environment when building configurations are properly designed, and the visual appearance is good (Chan and Lee 2008).

In contradiction with the existing literature that emphasises the significant role of urban form in creating socially sustainable neighbourhoods (e.g. Bramley et al. 2009; Dempsey, Brown, and Bramley 2012), our results show that of the four urban form factors, only quality of urban design and density had an influence on the overall urban social sustainability, but in opposite directions. While a better quality of urban design increased people's perceived overall urban social sustainability, higher density had a negative influence on their perception of urban social sustainability of their neighbourhood. The findings also revealed that quality of urban design was the most influential urban form factor, having significant positive associations with three of the USS dimensions. This finding underscores the importance of prioritising the strategies related to the development of urban design quality in order to enhance urban social sustainability (Carmona 2019). This is particularly important because, compared to other urban form strategies that are costly and difficult to implement in urban development projects, quality of urban design can be enhanced in a relatively short time and with a limited budget while having a significant influence on urban social sustainability.

\section{Personal Factors Associated with the Dimensions of Urban Social Sustainability}

Social interaction. Our results indicated that homeowners were more likely to interact with 
their neighbours and to participate in community activities, in that owning one's home may lead to higher residential stability and more investment in and commitment to the community (Evans 2009). There was a positive association between length of residence and the level of social interaction, with long-term residents being more engaged with their community and having more interaction with other members of the community (Dempsey et al. 2011; Rani 2012; Choguill 2008). Age was also found to be positively associated with social interaction, in that older and retired residents had more free time for social interaction and knew more neighbours, usually as a result of living in their community longer (Bramley et al. 2006; Fernández-Carro, Módenes, and Spijker 2015; Shirazi and Keivani 2019).

Social participation. Income level was found to be negatively associated with social participation. This is not surprising as previous research has found that higher-income residents tend to feel autonomous and distinguish themselves from other residents, which can result in their low willingness to interact with others and participate in community activities (Bramley et al. 2009; Dempsey et al. 2011). In contrast, Hagerty, Williams, and Oe (2002) argue that residents with low income are limited from participating in activities that promote social integration because they have a perception of being different, not fitting in, and not being valued.

Our results also confirmed a positive association between length of residence and people's social participation - a trend attributed by extant research usually to stronger social networks and more community involvement (Grillo, Teixeira, and Wilson 2010; Lewicka 2010). Low sense of participation and engagement in short-term residents may be because they know they are not going to stay long-term in the neighbourhood and therefore, they do not invest as much in their community (Rani 2012). In this regard, Smith (2011) states that shortterm residents are more concerned with setting up house, whereas long-term residents are more interested in the improvement of their community.

Sense of place. Based on our results, sense of place was positively associated with the length of residence in the neighbourhood, as it takes time to adjust to the new environment and find place in the new community. This finding supports prior research by Smith (2011) who found that an individual fosters a sense of place to a community through investing within "temporal (i.e., length of residence)", "economic (i.e., homeownership)", and "social (i.e., relationships)" aspects of the community (p. 75). Age had a significant relationship with sense of place in a way that older residents had more feelings of pride and attachment towards their neighbourhood usually as a result of living in their community longer (Fernández-Carro, Módenes, and Spijker 2015). 
Safety and security. Both length of residence and income had positive effects on people's perceived feeling of safety and security. High socio-economic residents perceive a higher feeling of safety and security because they can afford better security and are less exposed to criminal activities such as youth gangs or drug smuggling (Rani 2012; Hemani, Das, and Chowdhury 2017). High residential stability also had a positive influence on sense of safety, as it increases familiarity and confidence in movement in the neighbourhood (Cozens, Love, and Nasar 2015).

Neighbourhood satisfaction. Among the studied personal factors, income, length of residence, and homeownership had positive influence on neighbourhood satisfaction. The impact of people's economic status on satisfaction has been the subject of various studies, stating that more affluent residents experience higher neighbourhood satisfaction as they often have better access to different facilities and services and live in better houses (James, Carswell, and Sweaney 2009; Evans 2009). Furthermore, communities with low residential stability have been observed to have little opportunity or time to form networks and to develop a sense of attachment to place (Lewicka 2010; Karuppannan and Sivam 2011; Dave 2011). Homeownership was also linked to higher levels of neighbourhood satisfaction as it allows people to settle and facilitate a sense of financial security (James, Carswell, and Sweaney 2009; Bramley et al. 2006; Evans 2009).

\section{Conclusion}

This study makes various theoretical and practical contributions to the existing urban social sustainability literature. From a theoretical perspective, we contribute to the literature by proposing a measurement model for urban social sustainability (USS model) that addresses the fragmented conceptualisation of this concept and integrates its scattered dimensions into a coherent framework. Our conceptualisation of urban social sustainability incorporates six dimensions of social equity, neighbourhood satisfaction, social interaction, safety, sense of place, and social participation, aiming to capture a more comprehensive and interpretable picture of urban social sustainability at the neighbourhood scale. We also address the lack of robustness in previous urban social sustainability measures through undertaking a meticulous reliability, validity, and dimensionality analysis of the USS model. We show that urban social sustainability is a multidimensional phenomenon, and no single dimension can fully capture its complexity. In addition, we show that various dimensions of social sustainability are conceptually distinct and may have different antecedents, and hence, warrant different 
treatment and investigation.

The practical contributions of this study relate to operationalisation and incorporation of urban social sustainability into planning projects. We contribute to the current literature by investigating the impact of four selected physical (urban form) factors on different USS dimensions that can inform the development of more sustainable and liveable neighbourhoods. The value of this study is in its inclusion of a range of urban form factors that can facilitate (e.g., perception of quality of urban design) or hinder (e.g., perceived density) the level of urban social sustainability at the neighbourhood scale. We argue that previous studies have mainly focused on density, as the dominant measure of urban form (e.g., Dave 2011; Rani 2012; Bramley et al. 2006), and therefore, have overlooked the effects of other significant urban form factors such as quality of urban design and transport infrastructure. We also contribute to the literature by developing and validating a fine-grained and multidimensional measure of perceptual urban form at the neighbourhood scale. By placing the residents at the centre of urban form evaluation, this study provides insight into the question of how people perceive and evaluate their neighbourhood as a place to live. This subjective measure of urban form helps to minimise the potential mismatch between the researchers' interpretation of urban form and that of the residents. It also provides policymakers and urban planners with a better understanding of people's perceptions and expectations of urban environments and helps them address these needs more effectively and efficiently in the future plans of socially sustainable neighbourhoods. Acknowledging people's perceptions in a quantifiable manner can give power to participatory planning approaches, a growing requirement for planning practice that responds to public consent (Talen 2019). However, caution should be expressed in generalising our findings to cities of other countries as different residents in the same neighbourhood may have different accessibility and experiential needs and perceptions. It is important to note that achieving social sustainability in urban development is not just a matter of appropriate models and planning instruments, as urban form strategies need to comply with higher order policies and regulations (Darchen and Poitras 2020). There can be on-the-ground limitations such as potential conflicts between current planning agendas of intensification/economic revitalisation and social sustainability. A significant finding of this study is that different USS dimensions are not similarly influenced by personal and physical factors. For instance, two dimensions of social interaction and participation are least influenced by physical factors, while having positive associations with most of the personal factors. Additionally, two personal factors of length of residence and homeownership have a positive influence on overall social sustainability. The policy implication of this finding is that focusing on strategies to improve 
urban form factors is not enough for enhancing people's perceived levels of urban social sustainability. Policy should also be directed toward promoting people's social interaction and participation through organising more social events and empowering the communities and therefore increasing people's social ties and their satisfaction with their neighbourhood and community.

Our findings suggest that although urban form factors may contribute to social sustainability in urban environments, they are not the only predictors of people's perceived levels of urban social sustainability. For example, as expected, we found that people living in more wealthy and well-designed neighbourhoods with access to good quality housing and efficient public transport are more likely to experience higher levels of urban social sustainability. However, we also found that people living in the poorer neighbourhoods who struggle with different urban-form-related problems, such as poorly maintained streetscape and vehicle dominated streets, can also perceive high levels of urban social sustainability. This unexpected result may be explained by the role of personal factors such as length of residence in the neighbourhood or homeownership that can contribute to the formation of a strong sense of place and social ties with neighbours and, in turn, result in higher perceived urban social sustainability.

\section{Limitations and Directions for Future Research}

This study has some limitations and offers research directions for future studies. First, although we have made every attempt to include a broad set of dimensions in measuring urban social sustainability, we cannot claim that the USS model incorporates a fully exhaustive collection of criteria. Future studies may seek to modify or expand the USS model with additional dimensions and indicators, subject to the nature and scale of investigation or the contextuallyembedded requirements of case studies.

Second, this study does not allocate weights to physical and personal factors when investigating their relationship with USS dimensions. A fruitful avenue for research would be to incorporate weights to personal and physical factors based on people's perceptions of the significance of each of these factors to further align residents' needs and expectations of their neighbourhood to the strategic priorities of planners and policymakers.

Third, the transition of USS dimensions from hard measures to more intangible and soft measures over time highlights the dynamic nature of the phenomenon. Therefore, utilising a static research design is one of the limitations of this study, which may not enable us to fully 
grasp the inherent complexities of urban social sustainability. In light of this, future studies can extend the USS model by conducting a longitudinal study that portrays the trajectory of evolutions in USS dimensions and sheds light on the antecedents and consequences of development of urban social sustainability strategies in neighbourhoods over time.

Finally, it is worth noting that cities are dynamic entities, and therefore not only the relationship between urban form and social sustainability is idiosyncratic to each country, but the influence of urban form factors on people's feelings about their environment may vary over time. Therefore, this study suggests that urban planners and policymakers should avoid "one policy fits all" approach in their efforts to create socially sustainable urban spaces that meet people's needs and expectations. In line with this logic, the findings regarding the effects of personal and physical factors on different USS dimensions may not be directly applicable to cities of other countries that differ in size, population, and cultural context. Cross-country comparisons of the results and replication of this study in the context of other countries would be a fruitful avenue for future research that could further highlight differing perceptions and expectations of people in other urban contexts. It would also be valuable to extend the knowledge to investigate the relationship between urban form and social sustainability at other urban scales, such as city, region, and street, and compare the results with the neighbourhood scale. Under current circumstances, notions of urban sustainability are influenced by specific challenges and shocks, such as those recently experienced during the Covid-19 global pandemic. The interface of social sustainability dimensions with social resilience dimensions at the neighbourhood scale is a particularly timely research strand. 


\section{References}

Alexander, Don, and Ray Tomalty. 2002. "Smart growth and sustainable development: Challenges, solutions and policy directions." Local Environment 7 (4):397-409. Armitage, Rachel. 2017. Reducing Crime through Secured by Design: A Systematic Review. Paper presented at the Secured by Design - National Training Event, Northampton, UK.

Arundel, Rowan, and Richard Ronald. 2017. "The role of urban form in sustainability of community: The case of Amsterdam." Environment and Planning B: Urban Analytics and City Science 44 (1):33-53.

Bagozzi, Richard P, and Youjae Yi. 1988. "On the evaluation of structural equation models." Academy of Marketing Science 16 (1):74-94.

Boyko, Christopher T, and Rachel Cooper. 2017. "Density and sustainability." In Growing Compact: Urban Form, Density and Sustainability, edited by Joo Hwa Philip Bay and Lehman Steffen, 371-83. London: Routledge, Taylor \& Francis Group.

Bramley, Glen, Nicola Dempsey, Sinead Power, and Caroline Brown. 2006. What is 'social sustainability', and how do our existing urban forms perform in nurturing it. Paper presented at the Sustainable Communities and Green Futures, Bartlett School of Planning, University College London, London.

Bramley, Glen, Nicola Dempsey, Sinead Power, Caroline Brown, and David Watkins. 2009. "Social sustainability and urban form: Evidence from five British cities." Environment and Planning. A 41 (9):2125-42.

Burton, Elizabeth, and Lynne Mitchell. 2006. Inclusive urban design: Streets for life. Oxford, UK: Elsevier.

Carmona, Matthew. 2019. "Place value: Place quality and its impact on health, social, economic and environmental outcomes." Journal of Urban design 24 (1):1-48.

Chan, Edwin, and Grace KL Lee. 2008. "Critical factors for improving social sustainability of urban renewal projects." Social Indicators Research 85 (2):243-56.

Choguill, Charles L. 2008. "Developing sustainable neighbourhoods." Habitat International $32(1): 41-8$.

Colantonio, Andrea. 2016. "The challenge of social sustainability: Revisiting the unfinished job of defining and measuring social sustainability in an urban context." In Emergent Urbanism: Urban Planning \& Design in Times of Structural and Systemic Change, edited by Haas Tigran and Olsson Krister, 109-21. London, UK: Routledge. 
Cozens, Paul, Terence Love, and Jack L Nasar. 2015. "A review and current status of crime prevention through environmental design (CPTED)." Planning Literature 30 (4):393412.

Darchen, Sébastien, and Claire Poitras. 2020. "Delivering social sustainability in the innercity: the transformation of South-West Montreal, Quebec (Canada)." Local Environment 25 (4):305-19.

Dave, Seema. 2011. "Neighbourhood density and social sustainability in cities of developing countries." Sustainable Development 19 (3):189-205.

Dempsey, Nicola. 2009. "Are good-quality environments socially cohesive?: Measuring quality and cohesion in urban neighbourhoods." Town Planning Review 80 (3):31545.

Dempsey, Nicola, Glen Bramley, Sinéad Power, and Caroline Brown. 2011. "The social dimension of sustainable development: Defining urban social sustainability." Sustainable Development 19 (5):289-300.

Dempsey, Nicola, Caroline Brown, and Glen Bramley. 2012. "The key to sustainable urban development in UK cities? The influence of density on social sustainability." Progress in Planning 77 (3):89-141.

Dempsey, Nicola, Caroline Brown, Shibu Raman, Sergio Porta, Mike Jenks, Colin Jones, and Glen Bramley. 2010. "Elements of urban form." In Dimensions of the sustainable city, 21-51. London, UK: Springer.

Eizenberg, Efrat, and Yosef Jabareen. 2017. "Social sustainability: A new conceptual framework." Sustainability 9 (1):68.

Evans, Graeme. 2009. "Accessibility, urban design and the whole journey environment." Built Environment 35 (3):366-85.

Fernández-Carro, Celia, Juan Antonio Módenes, and Jeroen Spijker. 2015. "Living conditions as predictor of elderly residential satisfaction. A cross-European view by poverty status." European Journal of Ageing 12 (3):187-202.

Grillo, Michael C, Miguel A Teixeira, and David C Wilson. 2010. "Residential satisfaction and civic engagement: Understanding the causes of community participation." Social Indicators Research 97 (3):451-66.

Hagerty, Bonnie M, Reg Arthur Williams, and Hiroaki Oe. 2002. "Childhood antecedents of adult sense of belonging." Clinical Psychology 58 (7):793-801.

Hair, Joseph F, Rolph E Anderson, Barry J Babin, and Wiiliam C Black. 2010. Multivariate data analysis: A global perspective. Vol. 7. New Jersey, USA: Pearson Prentice hall. 
Hemani, Shruti, AK Das, and Anirban Chowdhury. 2017. "Influence of urban forms on social sustainability: A case of Guwahati, Assam." Urban Design International 22 (2):16894.

Jabareen, Yosef Rafeq. 2006. "Sustainable urban forms their typologies, models, and concepts." Planning Education and Research 26 (1):38-52.

James, Russell N, Andrew T Carswell, and Anne L Sweaney. 2009. "Sources of discontent residential satisfaction of tenants from an internet ratings site." Environment and Behavior 41 (1):43-59.

Jenks, Mike, Daniel Kozak, and Pattaranan Takkanon. 2013. World cities and urban form: Fragmented, polycentric, sustainable? London: Routledge.

Kärrholm, Mattias. 2011. "The scaling of sustainable urban form: A case of scale-related issues and sustainable planning in Malmö, Sweden." European Journal of Planning Studies 19 (1):97-112.

Karuppannan, Sadasivam, and Alpana Sivam. 2011. "Social sustainability and neighbourhood design: An investigation of residents' satisfaction in Delhi." Local Environment 16 (9):849-70.

Larimian, Taimaz. 2015. "Social sustainability: Towards some explanation." In Dialogues of sustainable urbanisation: Social science research and transitions to urban contexts, edited by Jenna M Condie and Anna M Cooper, 9-12. University of Western Sydney: Penrith.

Larimian, Taimaz, and Arash Sadeghi. 2019. "Measuring urban social sustainability: Scale development and validation." Environment and Planning B: Urban Analytics and City Science:1-17.

Larimian, Taimaz, Zahra Sadat Saeideh Zarabadi, and Arash Sadeghi. 2013. "Developing a fuzzy AHP model to evaluate environmental sustainability from the perspective of Secured by Design scheme-A case study." Sustainable Cities and Society 7 (3):2536.

Lewicka, Maria. 2010. "What makes neighborhood different from home and city? Effects of place scale on place attachment." Environmental Psychology 30 (1):35-51.

Lotfata, Aynaz, and Anlı Ataöv. 2019. "Urban streets and urban social sustainability: a case study on Bagdat street in Kadikoy, Istanbul." European planning studies:1-21.

Opp, Susan M. 2017. "The forgotten pillar: a definition for the measurement of social sustainability in American cities." Local Environment 22 (3):286-305. 
Rani, Wan Mohd. 2012. "Modelling the relationship between urban form and social sustainability in Malaysian cities: access to local services and public facilities." Heriot-Watt University.

Shaftoe, Henry. 2000. "Community safety and actual neighbourhoods." In Sustainable communities: The potential for eco-neighbourhoods, edited by $\mathrm{H}$ Barton. London, UK: Earthscan.

Shirazi, M Reza, and Ramin Keivani. 2017. "Critical reflections on the theory and practice of social sustainability in the built environment-a meta-analysis." Local Environment 22 (12):1526-45.

Shirazi, M Reza, and Ramin Keivani. 2018. "The triad of social sustainability: Defining and measuring social sustainability of urban neighbourhoods." Urban Research \& Practice:1-24.

Shirazi, M Reza, and Ramin Keivani. 2019. Urban Social Sustainability: Theory, Policy and Practice: Routledge.

Smith, Kylie M. 2011. "The relationship between residential satisfaction, sense of community, sense of belonging and sense of place in a Western Australian urban planned community." Edith Cowan University.

Talen, Emily. 1999. "Sense of community and neighbourhood form: An assessment of the social doctrine of new urbanism." Urban Studies 36 (8):1361-79.

Talen, Emily. 2019. "Plan vs. Process: The Case of Neighbourhood Planning." Built Environment 45 (2):173-89.

Vallance, Suzanne, Harvey C Perkins, and Jennifer E Dixon. 2011. "What is social sustainability? A clarification of concepts." Geoforum 42 (3):342-8.

Williams, Katie, Carol Dair, and Morag Lindsay. 2010. "Neighbourhood design and sustainable lifestyles." In Dimensions of the sustainable city, 183-214. London: Springer.

Wood, Lisa, Lawrence D Frank, and Billie Giles-Corti. 2010. "Sense of community and its relationship with walking and neighborhood design." Social Science and Medicine 70 (9):1381-90. 
Table A1. Summary of research studies on measures of urban social sustainability

\begin{tabular}{|c|c|c|c|}
\hline Author & Dimension & Indicators & Scale \\
\hline \multirow{3}{*}{$\begin{array}{l}\text { Yiftachel and } \\
\text { Hedgcock } \\
\text { (1993) }\end{array}$} & Equity & $\begin{array}{l}\text { - the concept of social balance and social mix and their role in the } \\
\text { development of community structures }\end{array}$ & \multirow[t]{3}{*}{ City } \\
\hline & Community & $\begin{array}{l}\text { - The character and dimensions of 'neighbourhood units' and the } \\
\text { facilities required to develop a community focus }\end{array}$ & \\
\hline & Urbanity & $\begin{array}{l}\text { - The layout and design of suburban areas and their impact on the } \\
\text { nature of social relations and behaviour }\end{array}$ & \\
\hline \multirow{5}{*}{$\begin{array}{l}\text { Barton } \\
(2000)\end{array}$} & Social provision & $\begin{array}{l}\text { - Access to facilities } \\
\text { - Access to built space }\end{array}$ & \multirow[t]{5}{*}{ Neighbourhood } \\
\hline & & - Access to open space & \\
\hline & & - Access to infrastructure & \\
\hline & Sustainability of & - Health & \\
\hline & neighbourhoods & $\begin{array}{l}\text { - Community safety } \\
\text { - Equity and choice }\end{array}$ & \\
\hline \multirow{9}{*}{$\begin{array}{l}\text { Burton } \\
(2003)\end{array}$} & Access to the superstores & $\begin{array}{l}\text { - Average distance to nearest superstore, from all wards, most- } \\
\text { deprived ward, and difference for most- and at least- deprived wards }\end{array}$ & \multirow[t]{9}{*}{ City } \\
\hline & Access to green space & $\begin{array}{l}\text { - Average distance to nearest green space, from all wards, most- } \\
\text { deprived ward, and difference for most- and at least- deprived wards }\end{array}$ & \\
\hline & Job accessibility & $\begin{array}{l}\text { - Percentage of low-income employees working outside the district, in } \\
\text { absolute and relative terms (compared with high-income groups) }\end{array}$ & \\
\hline & Public transport use & $\begin{array}{l}\text { - Percentage of low-income employees who travel to work by public } \\
\text { transport }\end{array}$ & \\
\hline & Extent of walking and cycling & $\begin{array}{l}\text { - Percentage of low-income employees who travel to work on foot or } \\
\text { bicycle, in absolute terms and relative to high-income employees }\end{array}$ & \\
\hline & Amount of living space & $\begin{array}{l}\text { - Rooms per household (average, and three-person, low-income } \\
\text { households); extent of overcrowding; inequality in housing size }\end{array}$ & \\
\hline & Health & - Death rate from mental illness (suicide rate) and respiratory disease & \\
\hline & Crime & $\begin{array}{l}\text { - Cost of home-contents insurance- all postcode sectors, worst sectors, } \\
\text { and difference between best and worst }\end{array}$ & \\
\hline & Segregation & $\begin{array}{l}\text { - Segregation, by ward, of ethnic households, owner-occupiers, local } \\
\text { authority tenants, car-less households and single-parent household, } \\
\text { average across all groups }\end{array}$ & \\
\hline
\end{tabular}


Affordable housing

Chiu (2003) Liveability
- Average price of lower-cost dwellings relative to average income of manual workers; average local authority rent; level of homelessness

- Cleanliness in the neighbourhood

- Internal housing condition

- External residential quality

- Access to open space

- Access to community facilities

- Noise level

- Affordability (private housing)

Equity in housing distribution and consumption

- Accessibility to housing marke

- Inadequately housed household

- Accessibility to public housing

- Adequacy of government subsidy in housing

- Social contact in the neighbourhood

- Visiting friends and family

- Walking activities/ strolling

- Safety and security

- Accessibility to the facilities

- Privacy and communal aspects

- Access to doctor/GP surgery

- Access to primary school

- Access to restaurant/café/takeaway

- Access to sports/recreation facility

- Access to community centre

- Access to facility for children

- Access to public open/green space

Sustainability of community

- Social interaction/social networks in the community

- Participation in collective groups and networks in the community

- Community stability

- Pride /sense of place

- Safety and security

- Average distance to nearest daily use shops, primary school, health facilities, open spaces and parks, transport nodes, bank, post office
Housing development

Neighbourhood

Neighbourhood

Neighbourhood 


\section{Amount of living space}

Health of the inhabitants

Community spirit and social interaction

Sense of safety

Neighbourhood as a a place to live in
- Average number of school, health facilities and open space and park

- Floor area per person

- Perceived level of satisfaction with the size of home

- Self-reporting of any outdoor private spaces within the home

- Self-reported health of the residents

- having stress related, pollution-related or no health problems

- Perceived number of social contacts (knowing people)

- Perceived number of informal chats with neighbours

- Self-reported involvement in various community activities at various

levels in the last 12 months

- Perceived friendliness of the neighbourhood

- Perceived safety within the neighbourhood during daytime

- Perceived safety within the neighbourhood after dark

- Perceived vandalism in the neighbourhood

- Perceived reputation of the neighbourhood

- Perceived neighbourhood in terms of attractiveness, architectural character, well maintained buildings, infrastructure, outdoors, parking facilities, quality of environment, cleanliness and general appearance

- Measured intensity of noise within the area

- Perceived problem of noise pollution within the neighbourhood

- Perceived privacy within the neighbourhood

- Residents' satisfaction with the neighbourhood as a place to live

- Desire to move out of the present home

- Provision of community space

- Transport links

- Place with distinctive character

- Integration with wider neighbourhood

- Accessible street layout

- Adaptable physical space for future development

- Perceptions of ability to influence local area

- Willingness to act to improve area

- Positive local identity

- Relationships with neighbours

- Well-being

- Feelings of safety

- Community facilities 
Colantonio
Social mixing, inclusion and cohesion

Well-being

Empowerment/participation

Identity, image and heritage
- Number of events and cultural activities encouraging interaction between people of varying ages, incomes, ethnicities and abilities

- Number of associations encouraging interaction between people of varying ages, incomes, ethnicities and abilities

- Number of public spaces frequented by residents of varying ages, incomes, ethnicities and abilities

- Number of informative 'training' workshops for newcomers

concerning the social qualities of the area

- Percentage of class or schools attended exclusively by pupils from ethnic minorities

- Percentage of schools attended by pupils from different income or background households

- Access to open space - average journey time for

residents/employees by foot (minutes)

- Access to leisure facilities - average journey time for

residents/employees by foot (minutes)

- Access to retail facilities - average journey time for residents/employees by foot (minutes)

- Access to entertainment facilities - average journey time for residents on foot (minutes)

- Proportion of registered electorate voting in national elections

- Proportion of registered electorate voting in local elections

- Number of local residents or their representative associations involved in the design of the scheme

- Number of local residents or their representative associations

involved in the implementation of local programmes and projects

- Number of local residents or their representative associations involved in the monitoring of the project

- Number of local associations

- Number of initiatives or attention centres for the elderly

- Number of initiatives and attention centres for ethnic minorities or immigrants

- Existence of local libraries and information centres

- Proportion of long-term residents

- Percentage of households owing their accommodation

- Percentage of households renting their accommodation

- Number of projects or programmes contributing to the enhancement

of buildings and areas of significant cultural or heritage value

- Number of commercial free public spaces 
Social capital

Equity of access to housing, education, and employment

Health and safety
- Number of adequate multi-faith places

- Percentage of people who have moved out of the area

- Number of groups, organizations, or associations operating in the area

- Number of voluntary organisations in the neighbourhood

- Number of local residents' regular meetings and gatherings in public buildings or spaces

- Numbers of social networks

- Number of jobs created (per 1000 square metres)

- Unemployment rate

- Average rent to income ratio

- Anti-poverty benefit uptake

- Deprivation index if available

- Percentage of children and people over 60 that live in households that are income deprived

- Number or Percentage of educational facilities within 500 meters of 15 minutes walk

- Percentage of children enrolled in schools outside the area

- Percentage of children in schools maintained by the local education authority

- Percentage of non-decent/unfit homes

- Affordable dwellings as percentage of new housing completions

- Proportion of a population within a 15 minutes walk or 500 metres of a health facility

- Number of hospital beds per 1000 residents

- Number of patients per General Practitioner (doctor)

- Incidence of specific disease

- Visits to General Practitioners (doctors) or other medical care

- Estimated proportion of drug-related accidents

- Number of anti-social behaviour accidents in the area

- Number of minor crimes per 1,000 inhabitants

- Number of serious crimes per 1,000 inhabitants

- Number of neighbourhood police officers per 1000 inhabitants

- Number of built-environment initiatives to improve local security (e.g. improved lighting system etc.)

- Social interactions and networks

- Trust/reciprocity
Neighbourhood 
Hemani,

Das, and

Chowdhury

Social equity

Opp (2017) Equal access and opportunity

- Equal access to job opportunities

- Equal access in connectivity and

transportation

- Equal education access and opportunity

- Procedural fairness

- Environmental justice index by census tract

Environmental justice and health risks

Community and the value of place

Basic human needs

Social network and interaction

Keivani

(2019)
- Health risk and well-being

- Social capital

- Social segregation

- Affordable housing

- Safety and security

- Fair distribution of income

- Number of neighbours known by name

- Frequency of meeting neighbours

- Number of friends in the neighbourhood

- Number of neighbours frequently visited

- Asking help from neighbours

- Exchange of help and support with neighbours

- Feeling of safety in daytime

- Feeling of safety after dark

- Safety of open spaces

- Children safety on the streets

- Safety of pavements and sidewalks

- Being victim of crime
City

Neighbourhood 
- Presence of police at the neighbourhood

Sense of attachment

- Feeling of neighbourhood attachment

- Neighbourhood proud

- Feeling of being at home in the neighbourhood

- Missing neighbourhood while away

- Desirability of neighbourhood

- Desire to leave the neighbourhood

Participation

- Knowing community-based organisations

- Membership in community organisations

- Participation in religious activities

- Being involved by local authorities

- Level of respond to local authorities

- Knowing neighbourhood problems

Quality of neighbourhood

- Perception of building crowding

- Perception of population crowing

- Satisfaction with noise pollution/neighbours/cleanliness of

neighbourhood/street lighting/maintenance of public

spaces/neighbourhood reputation/traffic congestion

Quality of home

- Satisfaction with home in terms of privacy/noise/room size/room number/parking

- Desire to move out

- Reason for moving 
Table A2. Viewpoints of researchers about dimensions of urban social sustainability at the neighbourhood scale

\begin{tabular}{l|cccccc}
\hline & $\begin{array}{l}\text { Social } \\
\text { Interaction }\end{array}$ & $\begin{array}{l}\text { Safety } \\
\text { S } \\
\text { Security }\end{array}$ & $\begin{array}{l}\text { Social } \\
\text { Equity }\end{array}$ & $\begin{array}{l}\text { Social } \\
\text { Participation }\end{array}$ & $\begin{array}{l}\text { Neighbourhood } \\
\text { Satisfaction }\end{array}$ & $\begin{array}{l}\text { Sense } \\
\text { of } \\
\text { place }\end{array}$ \\
\hline Barton (2000) & $\checkmark$ & $\checkmark$ & $\checkmark$ & $\checkmark$ & $\checkmark$ & $\checkmark$ \\
Bramley et al. (2009) & $\checkmark$ & $\checkmark$ & $\checkmark$ & $\checkmark$ & $\checkmark$ & $\checkmark$ \\
Dave (2011) & $\checkmark$ & $\checkmark$ & $\checkmark$ & & $\checkmark$ & $\checkmark$ \\
Colantonio (2016) & $\checkmark$ & $\checkmark$ & $\checkmark$ & $\checkmark$ & $\checkmark$ & $\checkmark$ \\
Hemani et al. (2017) & $\checkmark$ & $\checkmark$ & $\checkmark$ & $\checkmark$ & $\checkmark$ & $\checkmark$ \\
Shirazi and Keivani & $\checkmark$ & & & & & \\
(2019) & & $\checkmark$ & $\checkmark$ & $\checkmark$ & & $\checkmark$ \\
\hline
\end{tabular}


Table A3. Common definitions of urban form

Author Definition of urban form

Lozano (1990)

Williams et al. (2000)

Talen (2005, p. 206)

Jabareen (2006)

Jenks and Jones (2009) Urban form is a combination of the physical characteristics of a city.

Dempsey et al. (2012)

Tonkiss $(2014$, p. 2)

Urban form is comprised of repetitive urban patterns such as size and form of the buildings, street patterns, the configuration of public spaces, and etc.

Sustainable urban form includes the notion of compactness, traditional neighbourhood design, urban intensification, land use mix, and density.

At the intra-urban level, urban form can be defined as the physical pattern and structure of urban factors including streets buildings, spaces, lots, blocks, intersections, and the myriad ways in which these factors are used and configured

Urban form is an outcome of the combination of different concepts and factors of the urban space.

Urban form is defined through the structural form of the area (monocentric, polycentric or linear), the density of residential area (net, gross), the configuration of road network, the layout of blocks and housing units, the land use mix, the predominant type of buildings (single or multi-family units), the distribution of job and residential densities and the size of urban area measured by population (city, city-region or settlement).

Urban form is composed of material structures and physical spaces, but also and perhaps more fundamentally by social, economic, legal and political modes of organization and interaction. 
Table A4. Socio-economic and demographic information about each case study neighbourhood (Source: 2018 New Zealand census (Statistics New Zealand))

\begin{tabular}{|c|c|c|c|c|c|c|}
\hline Neighbourhood & Opoho & Caversham & $\begin{array}{l}\text { Green } \\
\text { Island }\end{array}$ & $\begin{array}{c}\text { Maori } \\
\text { hill }\end{array}$ & Concord & $\begin{array}{c}\text { Dunedin } \\
\text { City }\end{array}$ \\
\hline Location within the city & $\begin{array}{c}\text { Inner } \\
\text { area }\end{array}$ & $\begin{array}{l}\text { Middle } \\
\text { area }\end{array}$ & $\begin{array}{l}\text { Outer } \\
\text { area }\end{array}$ & $\begin{array}{l}\text { Inner } \\
\text { area }\end{array}$ & $\begin{array}{c}\text { Outer } \\
\text { area }\end{array}$ & \\
\hline Population & 1,218 & 2,265 & 2,319 & 2,448 & 1,512 & 126,255 \\
\hline Socioeconomic deprivation & 3 & 8 & 6 & 2 & 6 & \\
\hline $\begin{array}{l}\text { Number of occupied dwellings } \\
\text { counted }\end{array}$ & 483 & 1,032 & 948 & 933 & 564 & 48,627 \\
\hline $\begin{array}{l}\text { Unemployment rate in total } \\
\text { population aged } 15 \text { years and over }\end{array}$ & $4.8 \%$ & $5.1 \%$ & $3.8 \%$ & $3.3 \%$ & $4.0 \%$ & $4.3 \%$ \\
\hline $\begin{array}{l}\text { Median income of total } \\
\text { population aged } 15 \text { years and over } \\
\text { (per person) }\end{array}$ & $\$ 34,400$ & $\$ 23,400$ & $\$ 32,300$ & $\$ 37,700$ & $\$ 29,300$ & $\$ 25,500$ \\
\hline \multicolumn{7}{|l|}{ Ethnic groups } \\
\hline European ethnicity & $90.3 \%$ & $82.5 \%$ & $92.2 \%$ & $90.1 \%$ & $90.8 \%$ & $86.6 \%$ \\
\hline Maori ethnicity & $6.7 \%$ & $12.8 \%$ & $8.6 \%$ & $4.8 \%$ & $7.3 \%$ & $9.3 \%$ \\
\hline $\begin{array}{l}\text { Other ethnicity (Pacific, Asian } \\
\text { African, etc.) }\end{array}$ & $10.6 \%$ & $13.2 \%$ & $6.7 \%$ & $10.4 \%$ & $9.1 \%$ & $11.9 \%$ \\
\hline \multicolumn{7}{|l|}{ Family type } \\
\hline Couples with children & $41.1 \%$ & $34.9 \%$ & $41.0 \%$ & $41.5 \%$ & $40.1 \%$ & $38.6 \%$ \\
\hline Couples without children & $46.7 \%$ & $39.5 \%$ & $41.8 \%$ & $48.2 \%$ & $39.1 \%$ & $45.4 \%$ \\
\hline
\end{tabular}


Table A5. Information about respondents and urban form characteristics in each neighbourhood (Source: Household questionnaire survey)

\begin{tabular}{|c|c|c|c|c|c|c|}
\hline & & Opoho & Caversham & $\begin{array}{l}\text { Green } \\
\text { Island }\end{array}$ & $\begin{array}{l}\text { Maori } \\
\text { Hill } \\
\end{array}$ & Concord \\
\hline \multicolumn{2}{|c|}{ Number of respondents } & 49 & 53 & 50 & 48 & 51 \\
\hline \multicolumn{2}{|c|}{ Median age of respondents } & 38.3 & 31.6 & 43.8 & 50.2 & 37.3 \\
\hline \multicolumn{2}{|c|}{ Home-ownership rate } & $67.9 \%$ & $54.7 \%$ & $73.7 \%$ & $84.3 \%$ & $76.5 \%$ \\
\hline \multirow{4}{*}{$\begin{array}{l}\text { Length of } \\
\text { residence in the } \\
\text { neighbourhood }\end{array}$} & Less than 12 months & 10 & 1 & 2 & 3 & 7 \\
\hline & $1-4$ years & 15 & 10 & 11 & 10 & 12 \\
\hline & $5-10$ years & 6 & 17 & 13 & 9 & 8 \\
\hline & More than 10 years & 18 & 20 & 27 & 29 & 23 \\
\hline \multirow[t]{3}{*}{$\begin{array}{l}\text { Accommodation } \\
\text { type }\end{array}$} & $\begin{array}{l}\text { Detached/semi- } \\
\text { detached }\end{array}$ & 48 & 39 & 37 & 51 & 49 \\
\hline & Terraced house & 1 & 2 & 1 & 0 & 0 \\
\hline & Flat / unit & 0 & 7 & 15 & 0 & 1 \\
\hline \multirow{2}{*}{$\begin{array}{l}\text { Access to private } \\
\text { garden }\end{array}$} & Yes & 45 & 43 & 46 & 49 & 42 \\
\hline & No & 4 & 5 & 7 & 2 & 8 \\
\hline \multirow[t]{5}{*}{$\begin{array}{l}\text { Main means of } \\
\text { travel to work }\end{array}$} & $\begin{array}{l}\text { Private or company car } \\
\text { (includes both driving } \\
\text { and being a passenger) }\end{array}$ & $60.0 \%$ & $67.7 \%$ & $87.0 \%$ & $65.0 \%$ & $73.4 \%$ \\
\hline & Public bus & $6.4 \%$ & $5.8 \%$ & $3.1 \%$ & $1.9 \%$ & $3.4 \%$ \\
\hline & Bicycle & $6.0 \%$ & $2.0 \%$ & $0.5 \%$ & $1.7 \%$ & $2.1 \%$ \\
\hline & Walk or jog & $15.1 \%$ & $9.0 \%$ & $2.2 \%$ & $17.5 \%$ & $9.9 \%$ \\
\hline & Other & $12.5 \%$ & $9.1 \%$ & $7.2 \%$ & $13.9 \%$ & $11.2 \%$ \\
\hline
\end{tabular}


Table A6. Neighbourhood boundary map, Aerial map, and images of each case study neighbourhood

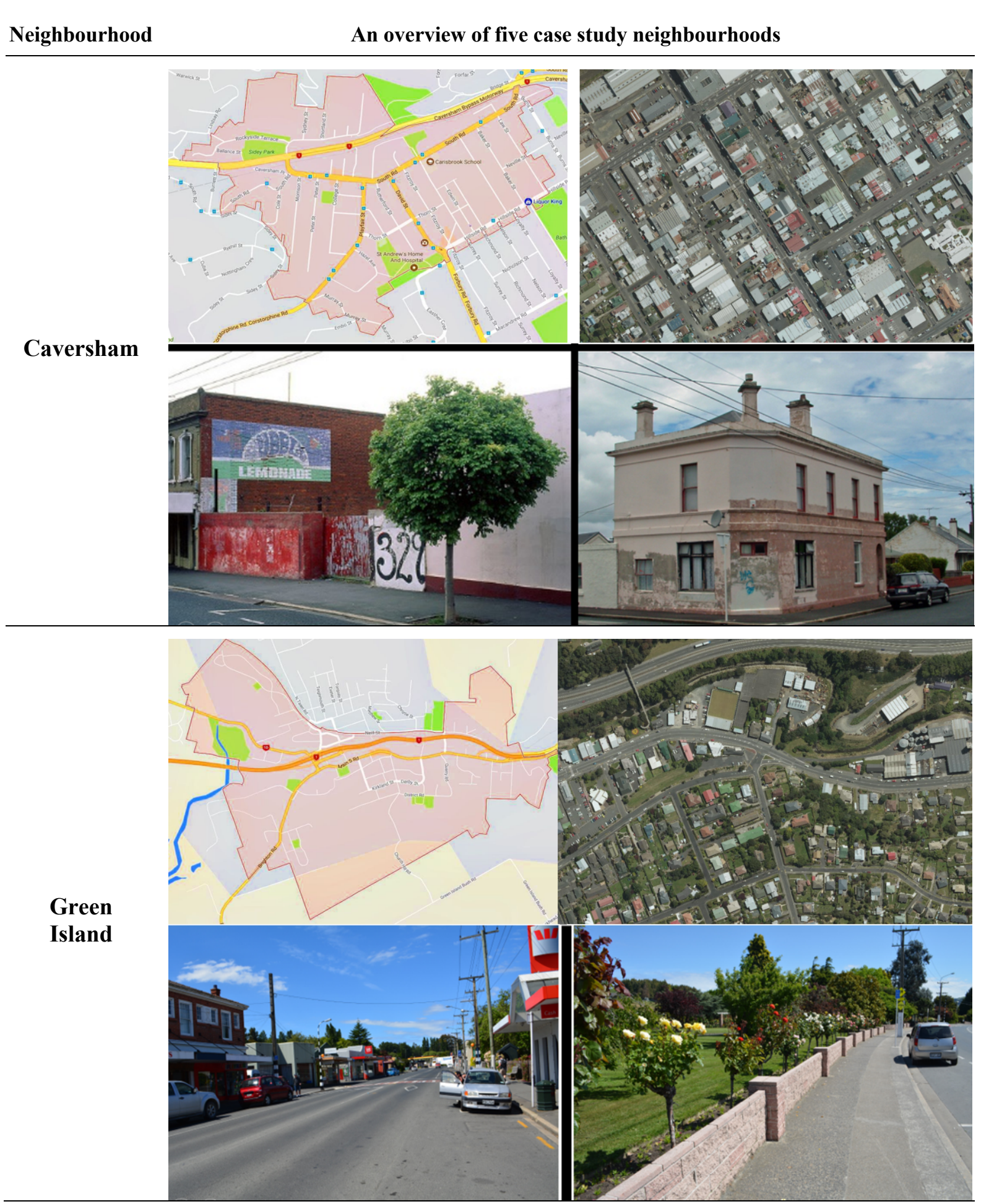



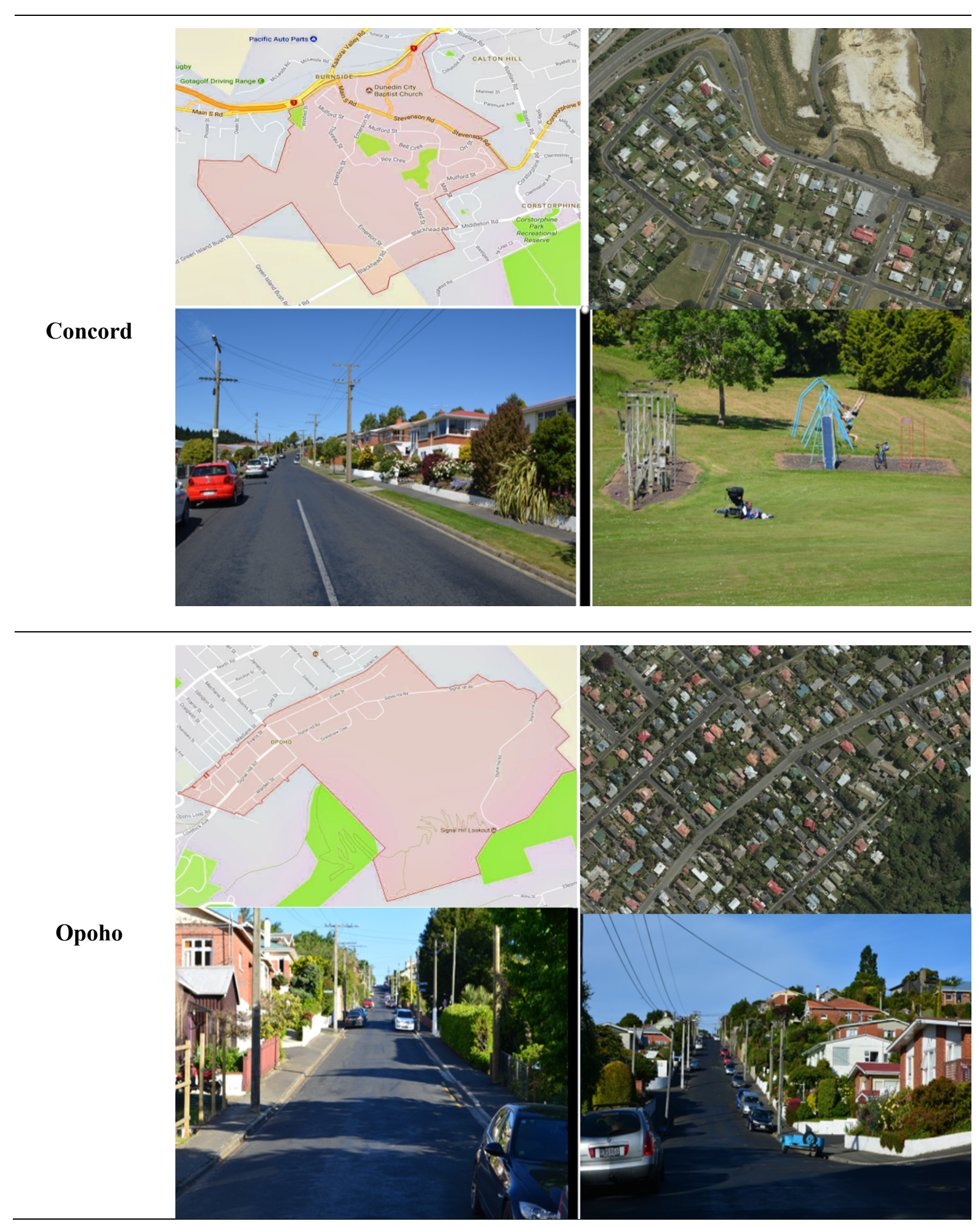


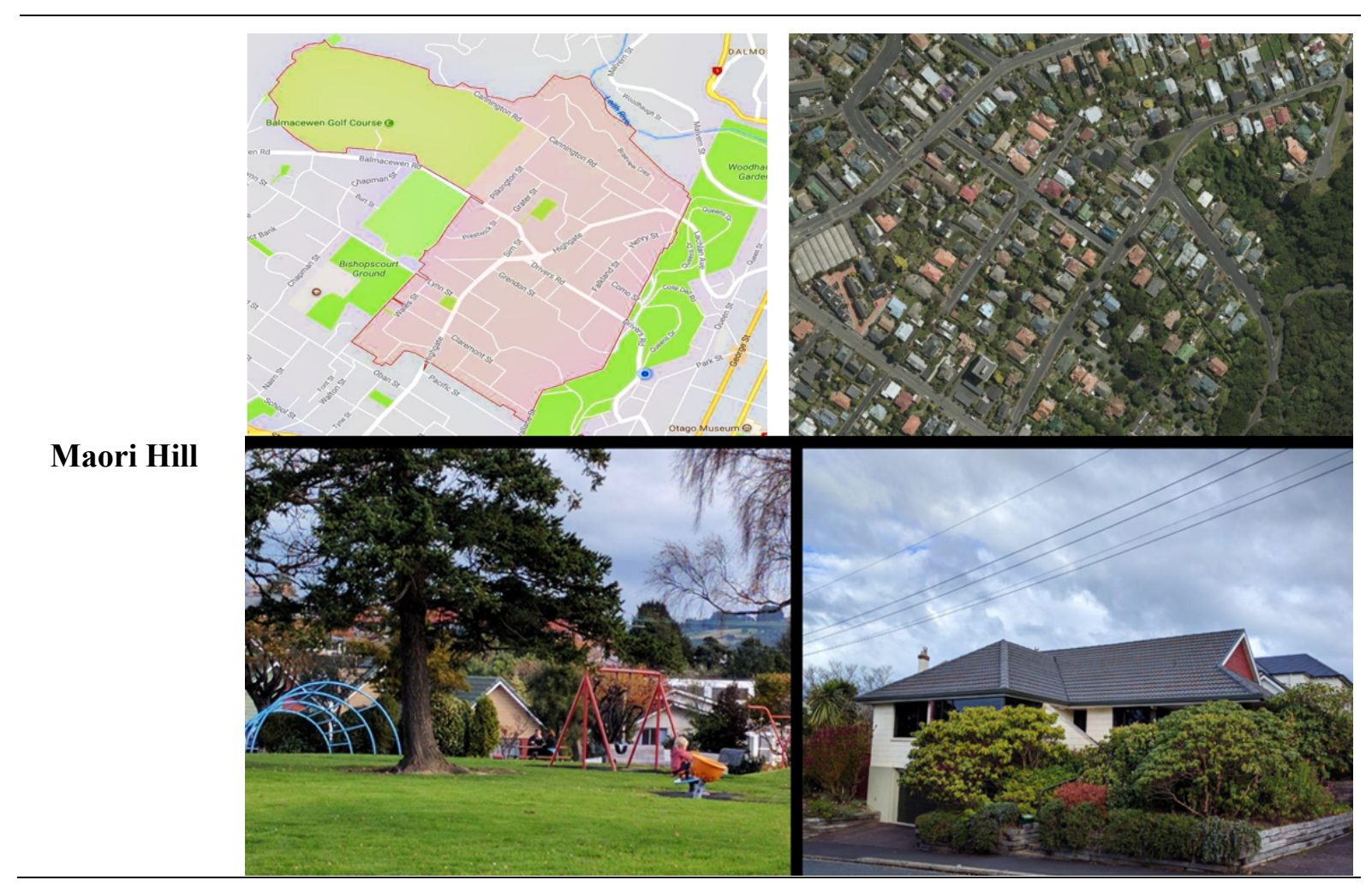




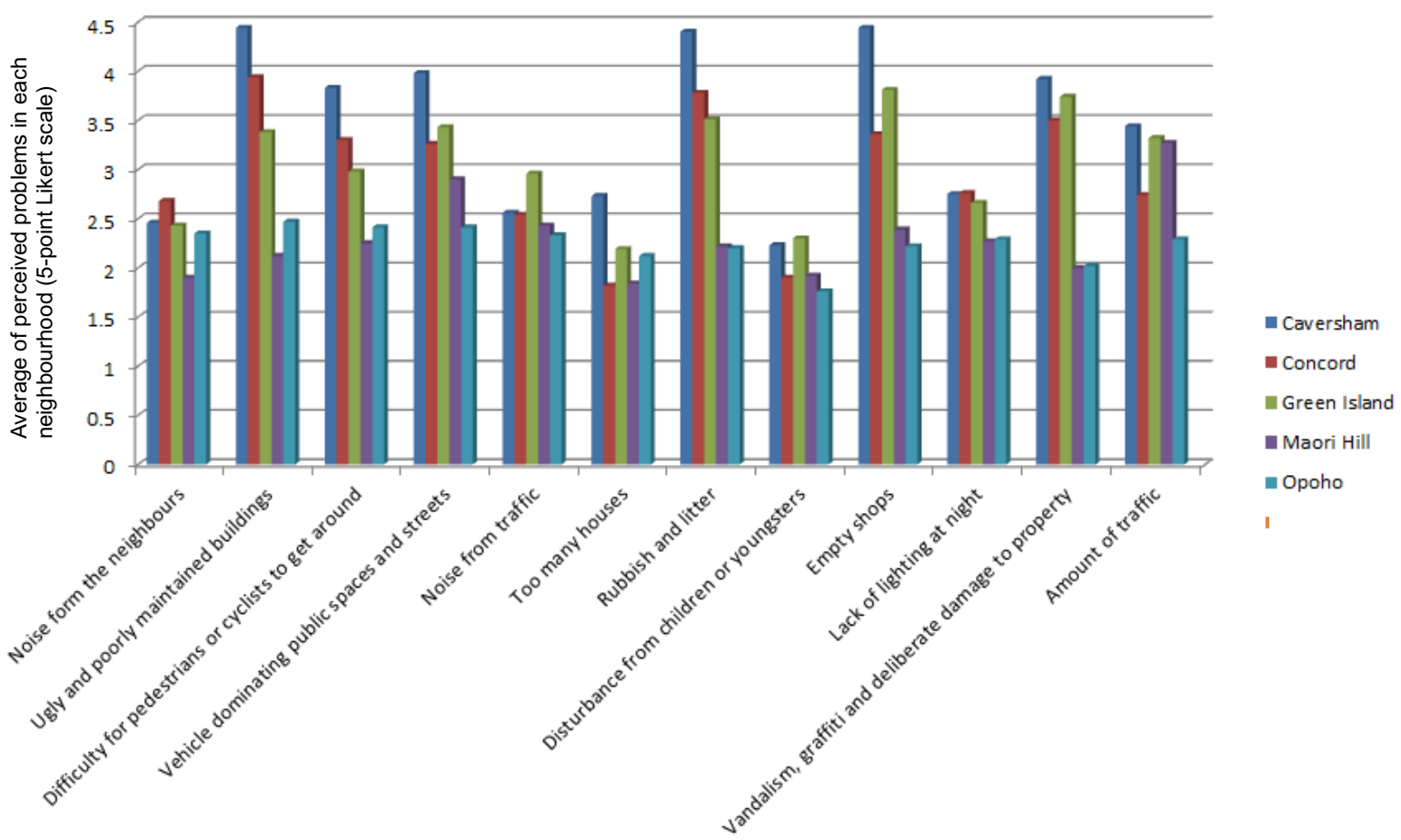

Figure A1. Significance of different problems in each neighbourhood (Source: Household questionnaire survey)

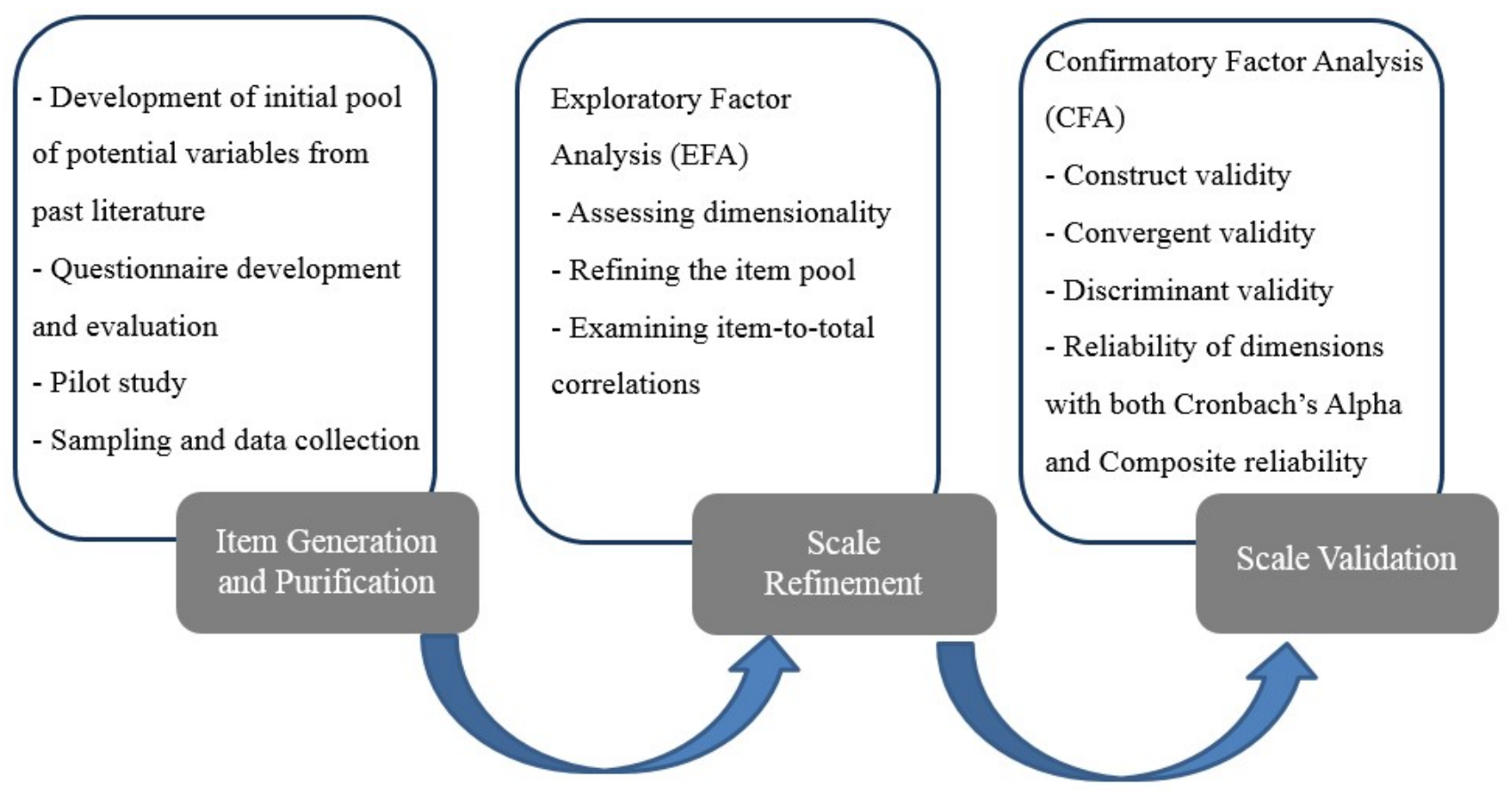

Figure A2. Different stages of using factor analysis 